\title{
Atmospheric Cold Front-Induced Exchange Flows through a Microtidal Multi-Inlet Bay: Analysis Using Multiple Horizontal ADCPs and FVCOM Simulations
}

\author{
Chunyan Li, Wei Huang, And Brian Milan \\ Department of Oceanography and Coastal Sciences, School of the Coast and Environment, \\ Louisiana State University, Baton Rouge, Louisiana
}

(Manuscript received 16 August 2018, in final form 14 December 2018)

\begin{abstract}
Atmospheric cold fronts provide recurring forcing for circulations and long-term transport in estuaries with microtides. Multiple horizontal ADCPs were used to obtain time series data from three inlets in Barataria Bay. The data cover a period of 51 atmospheric cold fronts between 2013 and 2015. The weather and subtidal ocean response are highly correlated in the "weather band" (3-7 days). The cold frontassociated winds produce alternating flows into, out of, and then back into the bay, forming an asymmetric "M" for low-pass filtered flows. Results show that cold front-induced flows are the most important component in this region, and the flows can be predicted based on wind vector time series. Numerical simulations using a validated Finite-Volume Coastal Ocean Model (FVCOM) demonstrate that the winddriven oscillations within the bay are consistent with the quasi-steady state with little influence of the Coriolis effect for cold front-related wind-driven flows. The four major inlets (from the southwest to the northeast) consistently carry $10 \%, 57 \%, 21 \%$, and $12 \%$ of the tidal exchange of the bay, respectively. The subtidal exchange rates through them however fluctuate greatly with averages of $18 \% \pm$ $13 \%, 35 \% \pm 18 \%, 31 \% \pm 16 \%$, and $16 \% \pm 9 \%$, respectively. Several modes of exchange flows through the multiple inlets are found, consisting of the all-in and all-out mode (45\% occurrence) under strong winds perpendicular to the coastline; the shallow-downwind, deep-upwind mode (41\%), particularly during wind-relaxation periods; and the upwind-in and downwind-out mode (13\%) under northerly or southerly winds. These modes are discussed with the low-pass filtered model results and verified by a forcing-response joint EOF analysis.
\end{abstract}

\section{Introduction}

Coastal Louisiana in the northern Gulf of Mexico (NGOM) has several major environmental processes that are determined by hydrodynamics, particularly those related to the exchange of water and sediment between estuaries and shelf water, land loss, and related barrier island evolution (FitzGerald et al. 2008). According to the USGS (e.g., Couvillion et al. 2011), Louisiana has $40 \%$ of the wetland of the United States and accounts for $90 \%$ of the nation's land loss due to processes causing net erosion (Penland et al. 1990; Britsch and Dunbar 1993; Roberts 1997; Barras et al. 2003; Penland et al. 2005; Palaseanu-Lovejoy et al. 2013). Along this coast, the most regular hydrodynamic

Corresponding author: C. Li, cli@lsu.edu motions are the relatively weak tides, which are mainly diurnal with a maximum tidal range of about $0.6 \mathrm{~m}$ (Harris 1981; Forbes 1988). This coast is characterized by semienclosed bays with exchange flows of water through multiple inlets. Because of the weak tides, the effect of weather (Stone et al. 2004; Khalil and Lee 2006; Day et al. 2007; Morton 2008; Otvos and Carter 2008; Morton and Barras 2011) becomes more prominent in moving the sediment through inundation and erosion (Dingler et al. 1993). As a result, the less predictable weather-induced bay oscillations may cause more significant flooding and draining of the microtidal system than those caused by tides (e.g., Houston et al. 1999; Hubbert and McInnes 1999; Peng et al. 2004, 2006; Xia et al. 2008).

Among the weather influences, hurricane impacts can be most dramatic. Because of the low gradient of land and relatively shallow and broad shelf, storm 
surges can cause significant damages, through physical forcing of storm surges and/or saltwater intrusions (Steyer et al. 2007; Mulrennan and Woodroffe 1998), which can adversely affect the vegetation (Pezeshki et al. 1990; Neubauer 2013; Xue et al. 2018). As some recent examples, severe storm surge caused damages in 2005 by Hurricanes Katrina and Rita (Fritz et al. 2007; Williams 2009; Williams and Flanagan 2009; Ebersole et al. 2010; Niedoroda et al. 2010), in 2008 by Hurricanes Gustav and Ike (Rego and Li 2009), in 2017 by Hurricanes Harvey (Shuckburgh et al. 2017) and Irma, and in 2018 by Hurricanes Florence and Michael.

However, hurricanes usually do not impact the same location with regularity. The associated damages are case dependent, and many studies have been done on the impact of hurricanes to the coast (e.g., Rego and Li 2010; Conner et al. 1989; Cahoon et al. 1995; Guntenspergen et al. 1995; Stone et al. 1997; Morton and Sallenger 2003; Fearnley et al. 2009; Smith et al. 2010; Morton and Barras 2011; Kent and Dokka 2013). In contrast, nonhurricane wind events are prevalent and have additional accumulative effect in driving the hydrodynamics and affecting the geomorphology (Roberts et al. 2015). There are numerous studies on wind-driven estuarine circulations, mostly in coastal plain estuaries (e.g., Wong 1994; Wong and Valle-Levinson 2002). Wind can play important roles in circulations (Valle-Levinson et al. 1998) and estuarine plumes (e.g., Valle-Levinson et al. 2007); however, there is a lack of examination of the effect of nonhurricane wind regimes as part of a meteorological system.

There is an entire category of synoptic-scale weather systems (extratropical cyclones and anticyclones) associated with centers of low and high pressures. Fronts with low air pressure extended from the center of a low pressure system are often formed between high pressure systems with different air masses. Along the fronts, there are usually strong wind shears. The dynamics of these systems influence the high and midlatitudes all over the world. The scale of these fronts is large compared to any coastal ocean and estuarine problems, as they typically stretch $2000-3000 \mathrm{~km}$ (Li et al. 2018a), and are much larger than the band of strong wind within a hurricane with a radius of maximum wind of only $50 \mathrm{~km}$ or less. Furthermore, the impact of atmospheric fronts is over a much larger area than the area of major influence of a major hurricane, albeit much stronger in wind forcing.

With a goal of quantifying the transport of water and waterborne materials, the conventional estuarine circulation studies usually focus on (e.g., de Miranda et al. 2017) the effects of density-driven flows, tidally driven flows, or individual wind events. The atmospheric fronts repeat quasi regularly especially in cold seasons (Roberts et al. 1989; Moeller et al. 1993; Chaney and Stone 1996; Walker 1996; Walker and Hammack 2000; Keen 2002; Pepper and Stone 2004) from the fall of each year to the following spring (Roberts et al. 2005; Feng and Li 2010; Lin et al. 2016; Li et al. 2018a). As a result, every year there are $\sim 20-30$ such significant frontal systems passing the area; most of them are cold fronts. The strong wind and wind shears force the water to oscillate, driving the water and sediment exchange with the coastal ocean. By analyzing data from three Louisiana bays, Feng and $\mathrm{Li}$ (2010) concluded that cold fronts generate significant bay-shelf water exchanges: cold front wind may flush more than $40 \%$ of the bay water out onto the continental shelf within a less than 40 -h period. The importance of cold fronts is further highlighted by the repeated impact of the same area every year and the integrated effects (Roberts et al. 2015), particularly in a region with microtides and severe erosion.

A recent study of $\mathrm{Li}$ et al. (2018a) examines the estuarine exchange flows in a 515-day time period, with 76 atmospheric cold or warm fronts or coldwarm front combinations (averaging $\sim 6.8$ days per event) passing the Louisiana coast. These fronts were found responsible for the flushing of bays through coastal tidal channels. As cold fronts and associated midlatitude cyclones are driven by the westerly winds, they usually sweep through the coasts of Texas, Louisiana, Mississippi, Alabama, and Florida sequentially. Therefore, the large-scale impact of cold fronts can be important when integrated over space and time, especially considering their overall ability in mobilizing water and sediment (Roberts et al. 2015).

Along the Louisiana coast, several bays have multiple narrow openings or multiple inlets. The impact of cold fronts on hydrodynamics in a multiple-inlet system is studied less compared to the effect of hurricanes. Some studies have examined tides in multipleinlet systems, focusing on the nonlinearity (e.g., Salles et al. 2005) or comparison with single-inlet systems for tidal and subtidal dynamics (Valle-Levinson et al. 2018). Such systems can modify the characteristics of tides and change the relative importance of diurnal and semidiurnal tides (Huang et al. 2002). Flows can be driven by the nonlinear interactions of the offshore tides, wind-induced currents, and morphology (Herrling and Winter 2015). Wind from a cold front passage can produce significant flows 


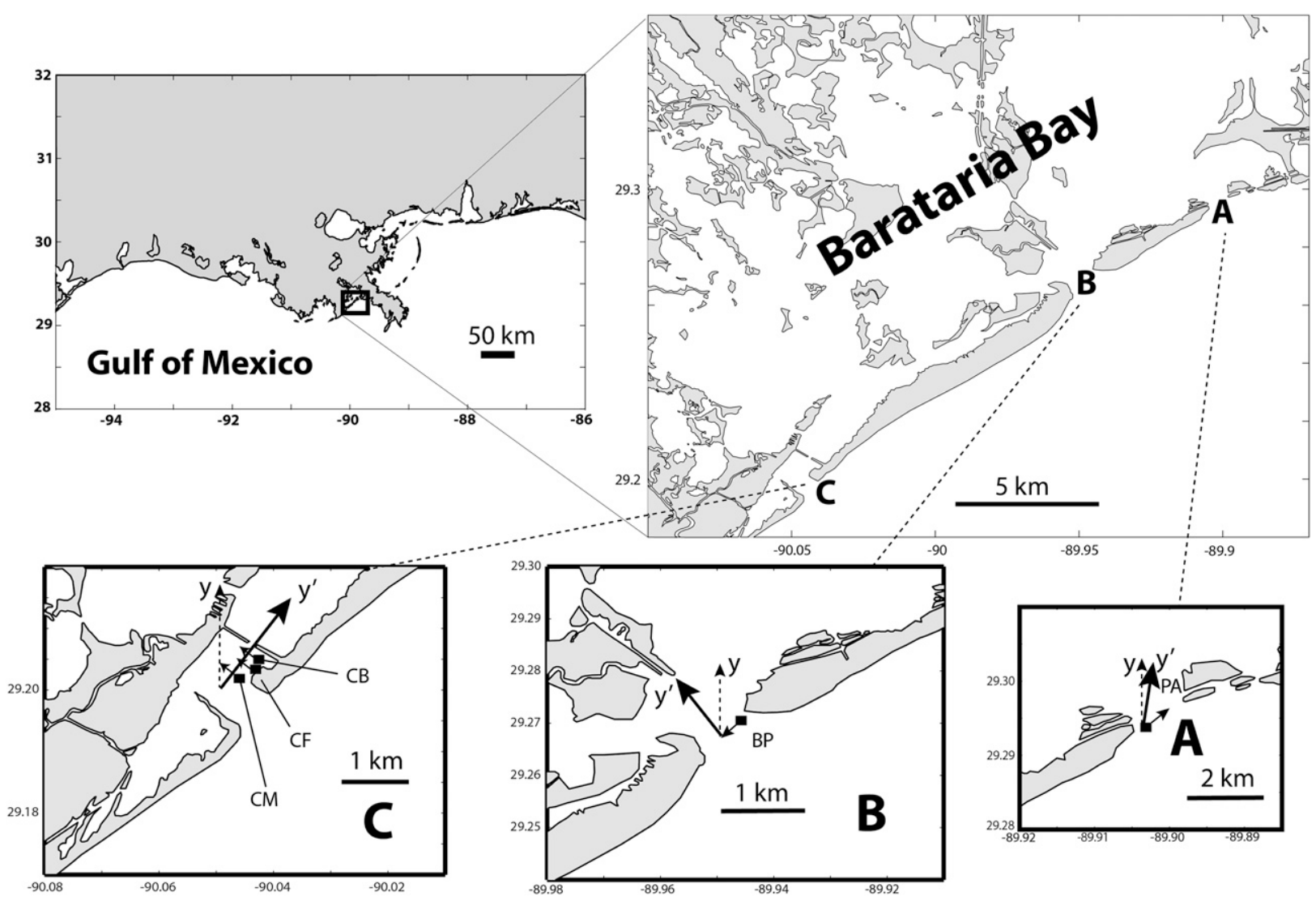

FIG. 1. Study area and locations of deployment of ADCPs. The areas marked as A, B, and C are Pass Abel (PA), Barataria Pass (BP), and Caminada Pass (CP), respectively. In the bottom panel labeled $\mathrm{C}$, the three squares marked by $\mathrm{CM}, \mathrm{CF}$, and $\mathrm{CB}$ are the locations at Caminada Pass in the midchannel, at the fishing pier, and boat dock, respectively. The arrows indicate the direction to which the transducers of the ADCP are facing.

overwhelming tidal effects (Li 2013; Huang and Li 2017). The effect of wind is determined by the depth, width, and location of the inlet and wind direction (Li 2013; Duran-Matute et al. 2016). A multiple-inlet system usually has only a limited connection with the continental shelf water through very narrow channels between the barrier islands, forming a lagoon. The narrow channels can act as dynamic filters reducing tidal fluctuations inside the lagoon system (Huang et al. 2002). The less predictable wind is found to be more important than the predictable tides in the sediment transport (Sassi et al. 2015) and the success of fish recruitment in such systems (Bruno and Acha 2015).

The main objectives of this paper are to use extended observations of velocity time series in multiple inlets of Barataria Bay to determine the effects of cold fronts in driving different modes of exchange flows. With a numerical simulation, we further investigate the mechanism and dynamical characteristics of the weather-induced bay oscillations and related tidal and subtidal exchange flows through the multiple inlets.

\section{Method}

\section{a. Study area}

Barataria Bay (Fig. 1) is an irregularly shaped shallow estuary with numerous islands inside the bay and several openings to the coastal ocean, bounded by barrier islands. Its horizontal scale is approximately $\sim 30-40 \mathrm{~km}$ in either the north-south or east-west directions, with the major axis oriented in the northwest-southeast directions. The bay is located to the south of New Orleans, Louisiana, and connected to the coastal ocean through several tidal inlets, including Caminada Pass ( $800 \mathrm{~m}$ wide and $9 \mathrm{~m}$ deep), which has a $90^{\circ}$ turn in channel orientation near the mouth, Barataria Pass ( $800 \mathrm{~m}$ wide and $20 \mathrm{~m}$ deep), Pass Abel $(15 \mathrm{~m}$ deep with broad shoals and a width of about $1.9 \mathrm{~km}$ ), and Quatre Bayou Pass (1.3 m deep and $2 \mathrm{~km}$ wide) as 

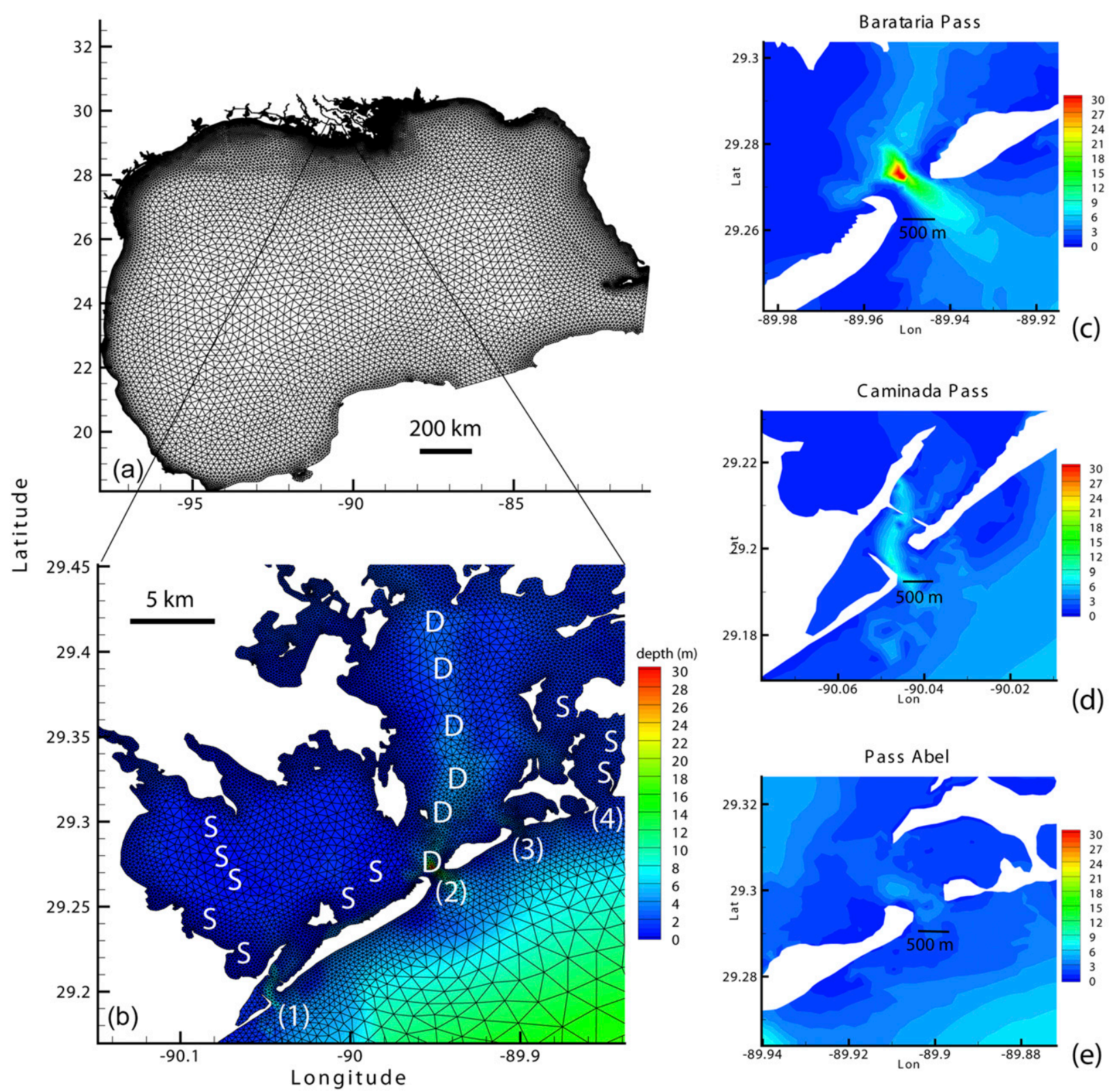

FIG. 2. Model mesh used for simulation. (a) The entire domain of simulation. (b) Zoomed-in view of Barataria Bay. The inlets (Caminada Pass, Barataria Pass, Pass Abel, Quatre Bayou) are marked by 1-4. The bathymetry is shown by the color contours (m). Some of the deep and shallow waters are marked by S and D, respectively, for convenience of discussion. (c)-(e) Further zoomed-in views showing the bathymetry of the inlets.

illustrated in Fig. 2. No measurements were made in the last inlet (Quatre Bayou). However, we have included it in a validated numerical model. Barataria Pass is the deepest among all the passes. Pass Abel, though wide, is mostly shallow except for a narrow channel on the western side. In general, Barataria Bay is shallow, with a mean depth of approximately $2 \mathrm{~m}$. The manmade Davis Pond Diversion facility located at $\sim 29^{\circ} 55^{\prime} 01^{\prime \prime} \mathrm{N}, 90^{\circ} 19^{\prime} 04^{\prime \prime} \mathrm{W}$ provides the main freshwater source for Barataria Bay (Li et al. 2011), which has a capacity of about $250 \mathrm{~m}^{3} \mathrm{~s}^{-1}$. An unusual $50-\mathrm{m}$ hole inside the bay northwest of the Barataria Pass entrance $\left(\sim 29^{\circ} 16^{\prime} 26^{\prime \prime} \mathrm{N}, 89^{\circ} 57^{\prime} 16^{\prime \prime} \mathrm{W}\right)$ found in one of our surveys is the deepest among all Louisiana lagoons, bays, and estuaries. This suggests potentially significant erosion due to strong currents from the narrow pass. In a microtidal system, the significant energy causing erosion should include those of the 
weather-related nontidal forcing in addition to those of tidal currents.

\section{b. Measurements}

Between November 2013 and March 2015, five Sontek Argonaut DP SL 500-KHz horizontal acoustic Doppler current profilers (ADCPs) were deployed at multiple inlets of the Barataria Bay system (Fig. 1) to measure velocity time series across the tidal passes. The ADCPs were deployed perpendicular to the flow, looking sideways. There were two periods of deployments: December 2013-February 2014 and December 2014-March 2015. One ADCP was deployed in Barataria Pass (BP) and another one in Pass Abel (PA). The ADCP at Barataria Pass was installed on the eastern end of the channel facing the southwest direction, while the ADCP at Pass Abel was installed on the western end facing the northeast (Fig. 1). In Caminada Pass, a total of three ADCPs were deployed. Among these three ADCPs, one was mounted on a fishing pier [Caminada Fish Pier $(\mathrm{CF})$ ] and one at a boat dock [Caminada Boat Dock (CB)]. They were all facing the center of the channel (roughly toward the northwest direction). The third one was deployed in the midchannel of Caminada Pass (CM) and only during the second period (i.e., 2014/15). The reason for deploying three ADCPs was an attempt to resolve possible spatial differences.

All the ADCPs were deployed at $\sim 2 \mathrm{~m}$ below the surface, looking horizontally. They were powered by a battery recharged during the day through a solar panel mounted on site. Each ADCP has two beams with slant angles of $25^{\circ}$ for the transducers. The data were saved at 5 -min ensemble intervals, except for the one installed in the midchannel of Caminada Pass, which had an ensemble average interval of $15 \mathrm{~min}$. The measurements were done acoustically along a horizontal line of about $100 \mathrm{~m}$ with 5 bins, each bin being $20 \mathrm{~m}$ in length. The blanking distance was $\sim 2 \mathrm{~m}$, and the first bin was $\sim 5 \mathrm{~m}$ from the transducer. All instruments recorded highquality data with no major gaps. In general, there was no obvious structure within the five bins, and the data from all five bins were averaged for the mean velocity along the $\sim 100$-m length. Here the lateral structure is ignored with a focus on the velocity averaged along the 100-m distance. Lateral structures at sub-100-m scales would be a subject of a separate study for fine features of individual channels. The only data excluded were those from Pass Abel during the second deployment in 2014/15 when the instrument was gradually buried under sand and data quality deteriorated in the latter part of the deployment. An example of the raw velocity time series is shown in Fig. 3.

The weather data are from the Grand Isle station of the National Ocean Service located at $29.265^{\circ} \mathrm{N}$, $89.958^{\circ} \mathrm{W}$, and the South Timbalier Block 52 station or Coastal Studies Institute (CSI) 6 (Allahdadi and Li 2017) maintained by the Wave-Current-Surge Information System (WAVCIS) Laboratory at Louisiana State University. The weather data from these stations have 6-min ensemble average intervals and are consistent in magnitude and temporal variations. The weather data from CSI 6 are only used to fill the gaps in the Grand Isle data, particularly in 2015. For convenience in discussing the along-channel flow velocity of water, the coordinate system is rotated first to be aligned with the principal component axis (which is basically the same as the main channel) of the data before analysis. This way, the major component will be along the channel because of the geometric constraint of a very narrow channel. A rotation of the coordinate system was made from the "east" direction sensed by the internal compass of the ADCP by about $-10^{\circ}, 52^{\circ}$, and $-45^{\circ}$ (Fig. 1), for Pass Abel, Barataria Pass, and Caminada Pass, respectively. In Fig 1 (in the bottom panels marked with locations A, $\mathrm{B}$, and $\mathrm{C}$ ), the direction after the rotation is denoted by $y$. Note that the rotation in Pass Abel of $-10^{\circ}$ was done along the local channel, which may look counterintuitive but it was verified with local survey and our time series data. The along-channel velocity component (in the direction of $y^{\prime}$ ) is always along the principal component direction, which is consistent with the channel orientations of these narrow inlets. The rotated along-channel velocity is positive when the flow is from the coastal ocean to the interior of the bay, and negative from the bay out to the ocean. Water-level data from NOAA at Grand Isle (station ID 8761724 at $29^{\circ} 15^{\prime} 8^{\prime \prime} \mathrm{N}$ and $89^{\circ} 57^{\prime} 4^{\prime \prime} \mathrm{W}$ ) are used for model validation.

\section{c. Tidal analysis}

Tides in the northern Gulf of Mexico are weak with microtidal ranges (maximum $0.6 \mathrm{~m}$ along the Louisiana coast and dominated by diurnal constituents; Kantha 2005). In contrast, currents through tidal passes can be swift under normal tidal conditions $\left(\sim 1.3 \mathrm{~m} \mathrm{~s}^{-1}\right.$ at Barataria Pass; Li et al. 2011) and after cold fronts $\left(2.6 \mathrm{~m} \mathrm{~s}^{-1}\right.$ at Vermillion Bay; Weeks et al. 2018), as these tidal passes are narrow channels with converging currents from the coastal ocean or the broad bay bounded by a series of barrier islands. As a result, tidal currents should not be ignored in the analysis of processes affected by the exchange flows. With the time series data for flow velocity, we can do harmonic analysis (Boon 2004) to quantify the tidal constituents. For that purpose and consulting NOAA's tide tables, the following eight major tidal constituents are selected for the harmonic analysis: $\mathrm{M}_{2}, \mathrm{~S}_{2}, \mathrm{~N}_{2}, \mathrm{~K}_{1}, \mathrm{O}_{1}, \mathrm{~S}_{1}, \mathrm{M}_{1}$, and $\mathrm{P}_{1}$ tides (Xu et al. 2010; Hill et al. 2011; Lin et al. 2016). 

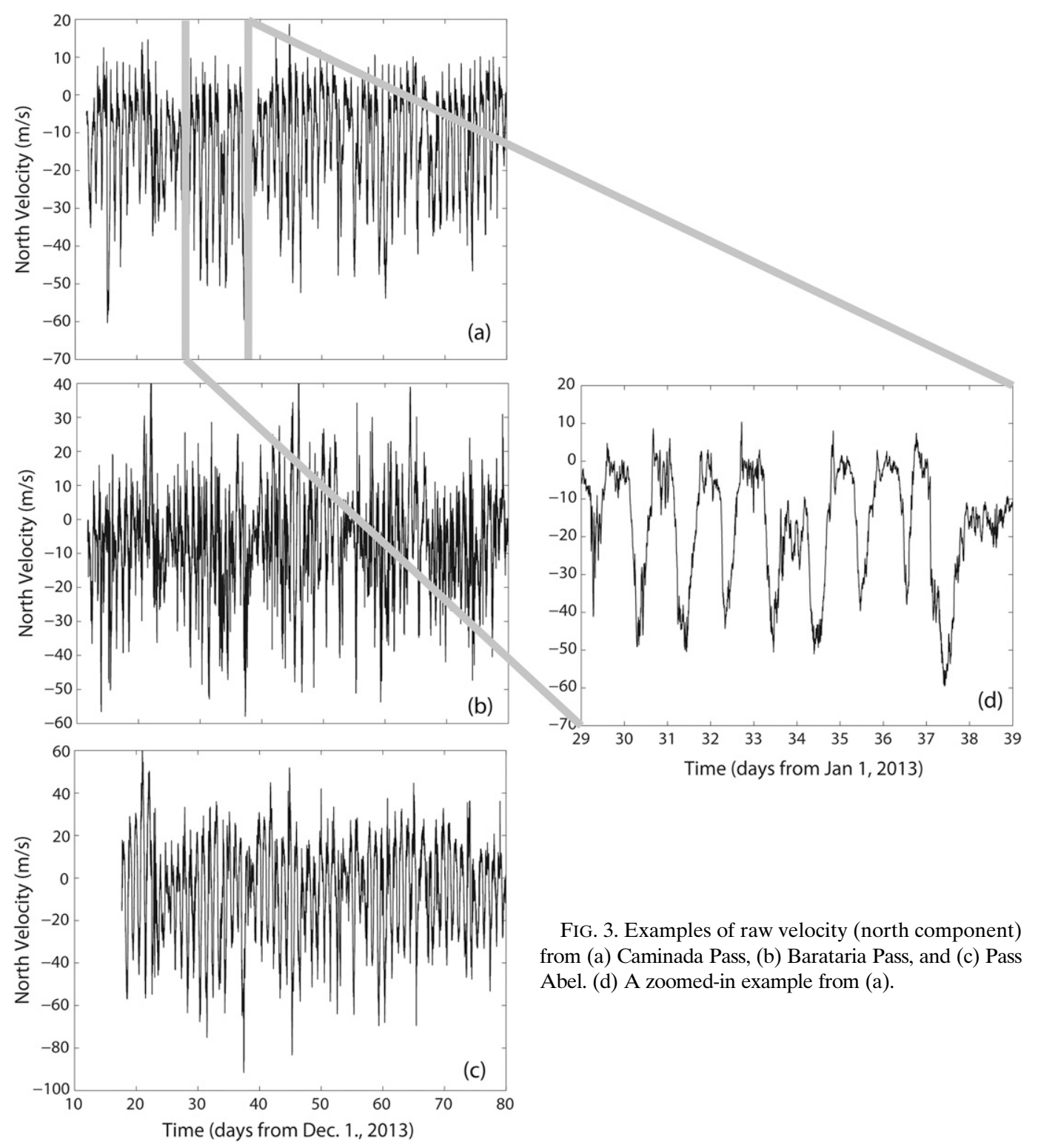

FIG. 3. Examples of raw velocity (north component) from (a) Caminada Pass, (b) Barataria Pass, and (c) Pass Abel. (d) A zoomed-in example from (a).

\section{d. Spectrum, correlation, and coherence analysis}

The spectrum is obtained with a fast Fourier transform (FFT) for the along-channel flow velocity component. The rotated flow velocity component is first low-pass filtered to retain the subtidal variations. The filtering is accomplished by a sixth-order Butterworth (Butterworth 1930; Emery and Thomson 2004) infinite impulse response (IIR) filter (Stearns and Hush 2011) with a cutoff frequency of 0.6 cycles per day (or $40 \mathrm{~h}$ ) that effectively takes out all the tidal and higher frequencies in the spectrum. The Butterworth filter is an effective recursive filter because of its smooth pass and stop bands and steep transition zone in the frequency response function (Roberts and Roberts 1978). The correlation coefficients between each forcing variable and subtidal current at each site during the observational periods (2013/14 and 2014/15) are calculated with or without time shift for examining the lag in time between the passage of the cold front and the significant change in subtidal flows. The spectra for weather-forcing factors (air pressure and north-south and east-west wind components) as well as the cross spectra between a forcing factor and subtidal current velocity for each site are also obtained, after which the calculation of the magnitude squared coherence (MSC) function is done. 
The MSC function is calculated based on the Welchaveraged periodogram method (Welch 1967).

\section{e. Identification of cold fronts and analysis}

By examining the weather maps from NOAA, the times of passage of cold fronts are identified (Table 1). Between 9 December 2013 and 21 February 2014, a total of 19 cold fronts are identified during the 70-day period. Between 12 November 2014 and 11 March 2015, a total of 32 cold fronts are identified during the 119 -day period. A total of 51 cold fronts are thus identified from 189 days of observations. With the identified approximate passing times of the cold fronts in the study area, we statistically examine the relationship between cold front conditions (or strength) and the subtidal exchange flows through the tidal passes.

\section{f. Numerical experiment}

Previous studies on processes in Barataria Bay using models have mainly used 2D models (Inoue et al. 2008) to address environmental issues such as the effects on shelf hypoxia and impact of freshwater diversion (Das et al. 2011, 2012). We select the 3D Finite-Volume Coastal Ocean Model (FVCOM; Chen et al. 2003) for numerical simulations of cold front-driven circulations in the area with a focus on the Barataria Bay. The model covers the entire Gulf of Mexico, roughly from $80.7^{\circ}$ to $97.9^{\circ} \mathrm{W}$ and from $18.1^{\circ}$ to $30.7^{\circ} \mathrm{N}$. The finest resolution is about $20 \mathrm{~m}$. There are 40 sigma vertical layers. It has two open boundaries (Fig. 2). Numerical simulations are done for the time period between 1 November 2013 and 28 February 2014 . The time step used for the external mode is $0.2 \mathrm{~s}$. The ratio of internal time step to external time step is 5 . The time interval for output is $30 \mathrm{~min}$. The tide is the only forcing function at the open boundaries provided by the Tide Model Driver (TMD) tide model (Padman and Erofeeva 2004), which includes a combination of 10 tidal constituents: $\mathrm{M}_{2}, \mathrm{~S}_{2}, \mathrm{~N}_{2}, \mathrm{~K}_{2}, \mathrm{~K}_{1}, \mathrm{O}_{1}, \mathrm{P}_{1}, \mathrm{Q}_{1}, \mathrm{M}_{\mathrm{f}}$, and $\mathrm{M}_{\mathrm{m}}$. The Climate Forecast System Reanalysis (CFSR) hourly data obtained from the National Centers for Environmental Prediction (NCEP) are used for atmospheric forcing (wind and air pressure). The original resolution for wind and air pressure data is $0.5^{\circ} \times 0.5^{\circ}$, from which the data are interpolated onto the FVCOM grid.

\section{g. Forcing-response joint EOF analysis}

To determine the modes with which the subtidal exchange flows respond to the cold fronts, we use a forcing-response joint empirical orthogonal function
TABLE 1. Time of cold front passages (using the closest weather map time).

\begin{tabular}{|c|c|c|c|}
\hline Year & Month & Day & Hour \\
\hline \multirow[t]{4}{*}{2013} & December & 9 & 12 \\
\hline & & 15 & 0 \\
\hline & & 23 & 0 \\
\hline & & 30 & 15 \\
\hline \multirow[t]{27}{*}{2014} & January & 2 & 12 \\
\hline & & 6 & 0 \\
\hline & & 11 & 22 \\
\hline & & 14 & 0 \\
\hline & & 15 & 12 \\
\hline & & 17 & 12 \\
\hline & & 19 & 12 \\
\hline & & 21 & 12 \\
\hline & & 24 & 0 \\
\hline & & 28 & 0 \\
\hline & February & 3 & 6 \\
\hline & & 5 & 3 \\
\hline & & 11 & 0 \\
\hline & & 15 & 3 \\
\hline & & 21 & 5 \\
\hline & November & 12 & 10 \\
\hline & & 17 & 5 \\
\hline & & 24 & 12 \\
\hline & & 27 & 5 \\
\hline & December & 3 & 12 \\
\hline & & 7 & 0 \\
\hline & & 10 & 10 \\
\hline & & 16 & 10 \\
\hline & & 18 & 0 \\
\hline & & 20 & 0 \\
\hline & & 24 & 0 \\
\hline & & 28 & 12 \\
\hline \multirow[t]{20}{*}{2015} & January & 4 & 3 \\
\hline & & 7 & 5 \\
\hline & & 10 & 3 \\
\hline & & 13 & 0 \\
\hline & & 18 & 12 \\
\hline & & 21 & 12 \\
\hline & & 23 & 5 \\
\hline & & 26 & 5 \\
\hline & & 30 & 5 \\
\hline & February & 2 & 5 \\
\hline & & 5 & 15 \\
\hline & & 10 & 1 \\
\hline & & 12 & 5 \\
\hline & & 15 & 12 \\
\hline & & 17 & 3 \\
\hline & & 19 & 10 \\
\hline & & 23 & 10 \\
\hline & & 26 & 16 \\
\hline & March & 5 & 11 \\
\hline & & 11 & 12 \\
\hline
\end{tabular}

(EOF) analysis. It is similar to the conventional EOF analysis (Emery and Thomson 2004) except that the subtidal wind components and the subtidal currents are grouped together in constructing the data matrix $\mathbf{Z}^{\prime}$ : 


$$
\mathbf{Z}^{\prime}=\left[\begin{array}{cccccc}
v_{r 1}\left(t_{1}\right) & v_{r 2}\left(t_{1}\right) & v_{r 3}\left(t_{1}\right) & v_{r 4}\left(t_{1}\right) & W_{E}\left(t_{1}\right) & W_{N}\left(t_{1}\right) \\
v_{r 1}\left(t_{2}\right) & v_{r 2}\left(t_{2}\right) & v_{r 3}\left(t_{2}\right) & v_{r 4}\left(t_{2}\right) & W_{E}\left(t_{2}\right) & W_{N}\left(t_{2}\right) \\
\vdots & \vdots & \vdots & \vdots & \vdots & \vdots \\
v_{r 1}\left(t_{n}\right) & v_{r 2}\left(t_{n}\right) & v_{r 3}\left(t_{n}\right) & v_{r 4}\left(t_{n}\right) & W_{E}\left(t_{n}\right) & W_{N}\left(t_{n}\right)
\end{array}\right],
$$

in which $v_{r 1}, v_{r 2}, v_{r 3}$, and $v_{r 4}$ are the subtidal (rotated) along-channel velocity component for the first (Caminada Pass), second (Barataria Pass), third (Pass Abel), and fourth (Quatre Bayou Pass) inlet, respectively; $W_{E}$ and $W_{N}$ are the east and north components of the subtidal wind velocity vector, respectively; and $t_{1}, t_{2}, \ldots$, and $t_{n}$ are times for the first, second, ..., and $n$th samples, respectively. The data matrix is then demeaned for each column to yield the mean data matrix $\mathbf{Z}$. The data scatter matrix is then constructed by $\mathbf{S}=\mathbf{Z}^{\mathrm{T}} \mathbf{Z}$. The eigenvalues and associated eigenvectors of $\mathbf{S}$ can then be calculated for the EOF modes and percentage of variability for each mode.

\section{Results}

\section{a. Tidal currents}

The semidiurnal tidal velocity amplitudes are all smaller than those for the diurnal tidal velocity at all sites, except $\mathrm{M}_{1}$ (Fig. 4a). The largest semidiurnal tidal velocity amplitude is the $\mathrm{M}_{2}$ tide, which ranges between $\sim 2$ and $5 \mathrm{~cm} \mathrm{~s}^{-1}$. The amplitudes for $\mathrm{K}_{1}, \mathrm{O}_{1}, \mathrm{~S}_{1}$, and $\mathrm{P}_{1}$ for the CF station are $19,15,17$, and $15 \mathrm{~cm} \mathrm{~s}^{-1}$, respectively. The largest diurnal constituents are from the midchannel station in CM with the amplitude for the $\mathrm{K}_{1}$, $\mathrm{O}_{1}, \mathrm{~S}_{1}$, and $\mathrm{P}_{1}$ tidal flow constituents being $\sim 35,26,6$, and $16 \mathrm{~cm} \mathrm{~s}^{-1}$, respectively. The smallest tidal flow amplitude for all the constituents is from the CB station, which has only half of the amplitude of that at the CF station for all the diurnal constituents. Among the diurnal tidal velocity constituents, $\mathrm{K}_{1}$ and $\mathrm{O}_{1}$ dominate the $C M$ station while $K_{1}, S_{1}$, and $P_{1}$ are important at the $\mathrm{BP}$ station. The mean along-channel velocity is between -16 and $-6 \mathrm{~cm} \mathrm{~s}^{-1}$; that is, the flow is out of the bay toward the coastal ocean at all inlets.

\section{b. Velocity spectrum}

The along-channel velocity spectrum from the FFT is discussed in five different frequency bands. The first two are the tidal and intertidal bands (Fig. 4b), which cover the diurnal $[0.8<f<1.1$ cycles per day (cpd)] and semidiurnal $(1.8<f<2.2 \mathrm{cpd})$ tidal constituents and all frequencies between these two groups (intertidal, or $1.1<f<1.8 \mathrm{cpd}$ ). The $\mathrm{P}_{1}, \mathrm{~S}_{1}$, and $\mathrm{K}_{1}$ tidal frequencies are close to each other. They combine to form the highest peak (Fig. $4 \mathrm{~b}$ ). The $\mathrm{M}_{2}$ and $\mathrm{S}_{2}$ constituents are significant, while the value at $\mathrm{N}_{2}$ is small, comparable to the noise level. Nonlinearity introduces compound frequencies (Gallo and Vinzon 2005), which essentially broaden the diurnal and semidiurnal bands in the frequency domain. The third frequency band (Fig. 4c) is a collection of the higher-harmonics tidal constituents (such as $\mathrm{M}_{4}, \mathrm{M}_{6}$, and $\mathrm{M}_{8}$ tides; Pugh 1987) caused by nonlinearity of the dynamics due to advection, quadratic bottom friction, and finite surface elevation (e.g., Parker 1984). The spectrum obviously confirms the existence of these bands, referred to as overtides (Dronkers 1964; Dyer 1997; Gallo and Vinzon 2005), in the frequency domain. Here, the range $2.2<f<8$ cpd covers the overtides, that is, those above the semidiurnal frequencies but lower than $\mathrm{M}_{8}(\sim 8$ cycles per day), representing the band with most of the nonlinear effect in shallow waters. The spectrum with frequencies higher than $\mathrm{M}_{8}$ is classified as "noise" because of the small magnitude in the background and thus is excluded in the comparison.

In the low-frequency band $(f<0.8 \mathrm{cpd})$, there are several long-period tides: 1) the $M_{m}$ or lunar monthly constituents with a frequency of $0.0363 \mathrm{cpd}, 2)$ the $M_{\text {sf }}$ or lunisolar synodic fortnightly constituent with a frequency of $0.0677 \mathrm{cpd}$, and 3) the lunisolar fortnightly constituent at $0.0732 \mathrm{cpd}$. Thus, the fourth frequency band (Fig. 4d) is defined as the subtidal band $(f<0.8 \mathrm{cpd}$, excluding $f=0.0363,0.0677$, and $0.0732 \mathrm{cpd}$ ), in which weather-forcing factors (wind and air pressure) dominate. Therefore, the spectra for the along-channel velocity, air pressure, and wind velocity components are presented together for comparison.

It is shown that the peaks of the spectra for wind velocity components and air pressure mostly correspond to those of the flow velocity. This suggests some causeeffect relationship, which is not surprising as the subtidal weather forcing has been demonstrated to generate subtidal estuarine circulations or bay oscillations (e.g., Wilson et al. 1985; Wilson and Filadelfo 1986). In addition, we note that, aside from these low-frequency tidal constituents, all the other low frequencies in this band appear to be randomly distributed. The last (fifth) band is the mean (zero frequency).

\section{c. Partitioning of current regimes}

With the above definitions of five frequency bands, we examine the partitioning of the strength of current 
(a)

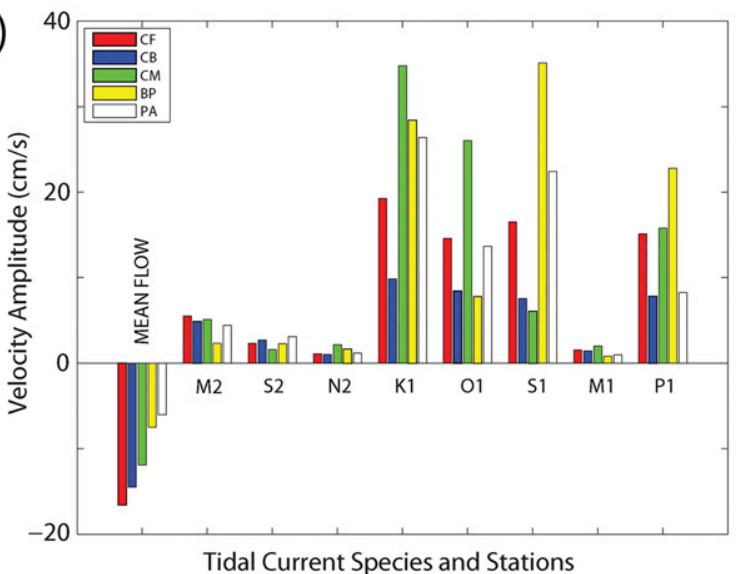

(c)

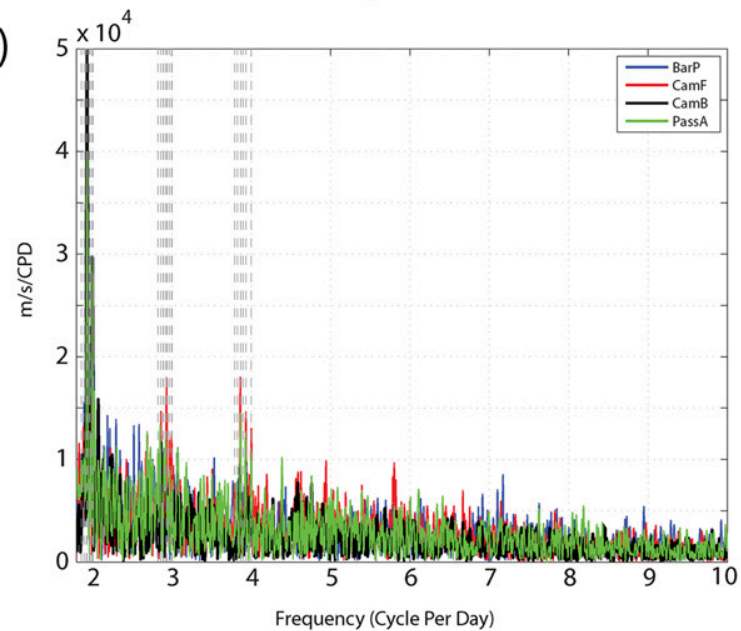

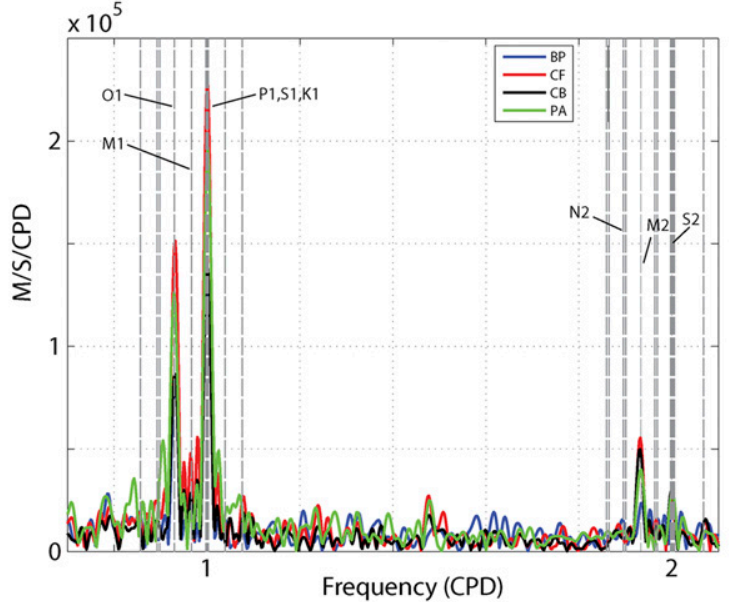

(b)

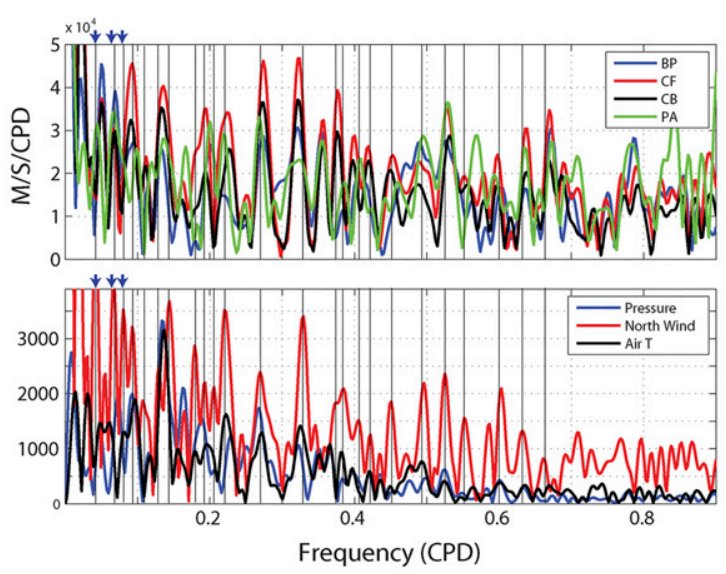

(d)

FIG. 4. (a) Tidal velocity amplitude at CF, CB, and CM of CP, BP, and PA. (b) Tidal and intertidal bands of the spectrum for the alongchannel velocity. (c) The overtide bands of the spectrum for the along-channel velocity. The unmarked lines are compound tides generated by nonlinearity. (d) The subtide bands of the velocity spectrum are shown in the upper panel and that for air pressure, wind speed, and air temperature in the lower panel. The vertical bars indicate the frequencies of the peaks in wind spectrum, extended into those of the flows for comparison.

velocity among these bands. We aim at examining the strength of current velocity in the low-frequency band that is contributed by weather and those caused by astronomical tides. For that purpose, within the spectrum, using the magnitude of velocity amplitude at a given frequency as a measure of the strength of velocity at that frequency, the integrated magnitude within different bands are calculated for comparison:

$$
V_{j}=\sum_{f \in b_{j}}\left|F_{u}(f)\right|, \quad(j=1,2,3,4,5)
$$

in which $F_{u}$ is the Fourier transform of along-channel velocity component $u$. Here $j=1,2,3$, 4, and 5 represent the band number for the tidal, subtidal, overtidal, and intertidal bands and the mean, respectively; $b_{j}$ is the collection (or range) of frequency of the $j$ th frequency band.
The integrated magnitudes in the along-channel velocity spectrum for the five bands defined above are calculated and normalized by the total of the five bands using

$$
v_{j}=\frac{\sum_{f \in b_{j}}\left|F_{u}(f)\right|}{\sum_{i=1}^{5} \sum_{f \in b_{i}}\left|F_{u}(f)\right|}, \quad(j=1,2,3,4,5) .
$$

All the five bands $\left(v_{j}, j=1,2,3,4,5\right)$ should add to 1 . The result shows that the tidal band at any of the stations has about $\sim 22 \%-29 \%$ of all the five bands added together for both datasets. The subtidal band is $\sim 23 \%-31 \%$. The overtidal band has $\sim 34 \%-43 \%$. This band between the semidiurnal and $\mathrm{M}_{8}$ tides is the widest among all five bands and has the largest values of all five bands. The broadband noise and all nontidal 


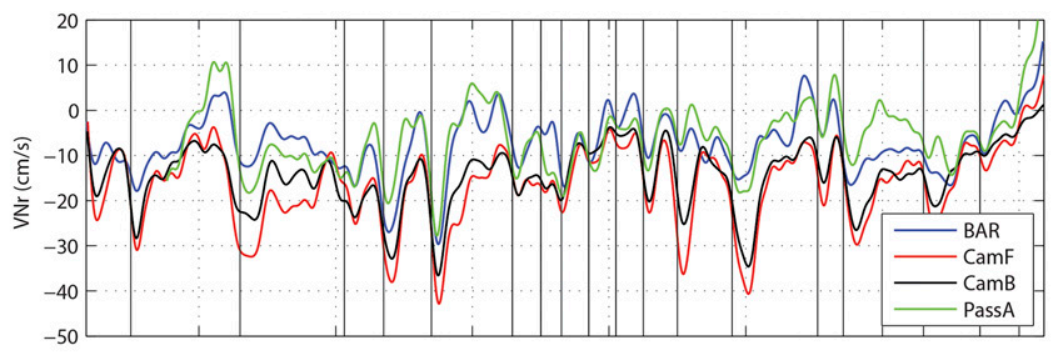

(a)

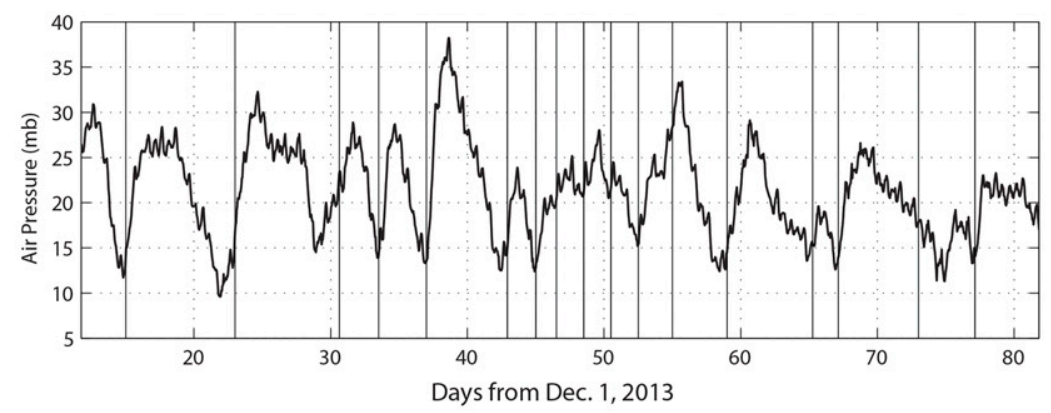

(b)

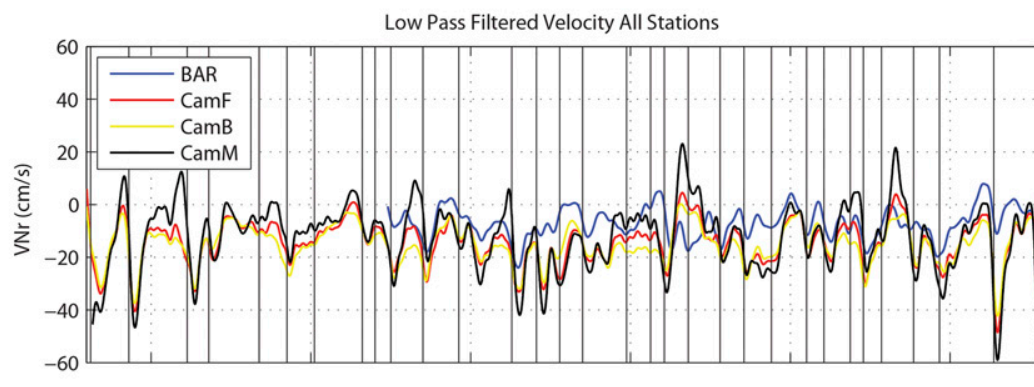

(c)

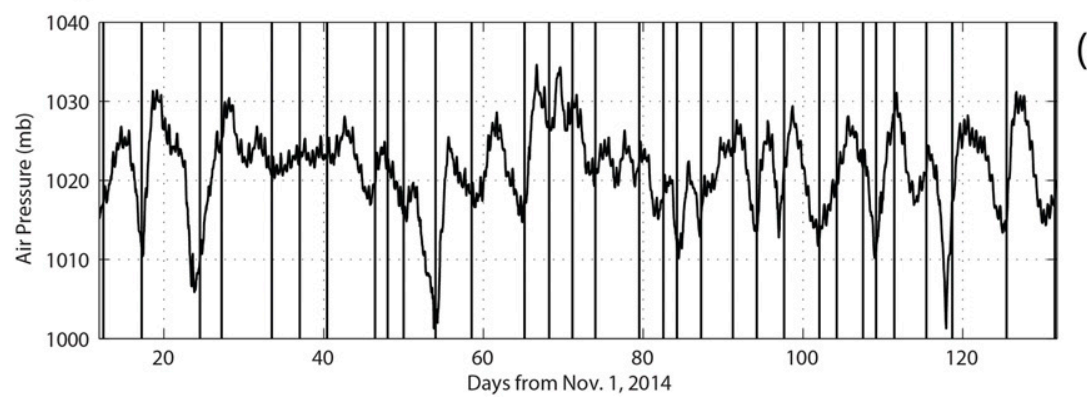

(d)

FIG. 5. (a) Low-pass filtered along-channel flow velocity from CF, CB, BP, and PA for the 2013/14 period and (b) air pressure. (c),(d) As in (a) and (b), but for the 2014/15 period for $\mathrm{CF}, \mathrm{CB}, \mathrm{BP}$, and $\mathrm{CM}$.

high-frequency motions are in this band. The intertidal band has about $9 \%-11 \%$, while the mean band is less than $1 \%$. The ratio between the subtidal and tidal bands shows that the two are generally comparable in magnitude, with the former being slightly larger for most stations: $2 \%-20 \%$ larger except the Pass Abel station where the subtidal band has $18 \%$ less magnitude.

\section{d. Subtidal response}

The subtidal flows (Fig. 5) fluctuate significantly each time the air pressure has a low value (corresponding to cold front passages). The timing of a frontal passage is closely related to the minimum air pressure and the timing of an abrupt change in wind direction (Fig. 5). The vertical lines in Fig. 5 are the times of cold front passages. There are other factors involved such as the nonlinear tides that drive subtidal flows (Ianniello 1977, 1979). These however are proportional to tidal amplitudes ( $\mathrm{Li}$ and O'Donnell 2005), which are small in the microtidal region. Nonlinear effects induced by weather-driven motions also increase with wind, which must have been included in the results. 
TABLE 2. Lagged correlation: time series 1.

\begin{tabular}{|c|c|c|c|c|c|c|}
\hline \multirow{2}{*}{$\frac{\text { Forcing }}{\text { Air pressure }}$} & \multirow{2}{*}{$\frac{\text { Response (subtidal flow) }}{\mathrm{CF}}$} & \multirow{2}{*}{$\begin{array}{l}\text { No lag } \\
-0.355\end{array}$} & \multirow{2}{*}{$\begin{array}{c}\text { Lagged max } \\
-0.590\end{array}$} & \multicolumn{2}{|c|}{$95 \%$ confidence interval } & \multirow{2}{*}{$\frac{\text { Lag (days) }}{0.677}$} \\
\hline & & & & -0.160 & -0.999 & \\
\hline & $\mathrm{CB}$ & -0.225 & -0.486 & -0.164 & -0.808 & 0.778 \\
\hline & BP & -0.101 & -0.426 & -0.108 & -0.744 & 0.799 \\
\hline & PA & -0.129 & -0.515 & -0.175 & -0.855 & 0.865 \\
\hline Average & & -0.202 & -0.504 & -0.152 & -0.852 & 0.780 \\
\hline \multirow[t]{4}{*}{ North wind } & $\mathrm{CF}$ & 0.745 & 0.820 & 0.438 & 1.000 & 0.306 \\
\hline & $\mathrm{CB}$ & 0.669 & 0.741 & 0.390 & 1.000 & 0.316 \\
\hline & $\mathrm{BP}$ & 0.610 & 0.694 & 0.364 & 1.000 & 0.323 \\
\hline & $\mathrm{PA}$ & 0.590 & 0.690 & 0.370 & 1.000 & 0.351 \\
\hline Average & & 0.653 & 0.736 & 0.391 & 1.000 & 0.324 \\
\hline \multirow[t]{4}{*}{ East wind } & $\mathrm{CF}$ & 0.024 & 0.220 & -0.090 & 0.530 & 0.788 \\
\hline & $\mathrm{CB}$ & -0.011 & 0.172 & -0.088 & 0.432 & 0.844 \\
\hline & BP & -0.290 & 0.127 & -0.073 & 0.327 & 1.014 \\
\hline & $\mathrm{PA}$ & -0.446 & 0.096 & -0.056 & 0.248 & 1.139 \\
\hline Average & & -0.181 & 0.154 & -0.0767 & 0.384 & 0.946 \\
\hline
\end{tabular}

Typical cold front weather usually shows prefrontal southerly or southeasterly winds originating from the warm and moist Gulf of Mexico; while the postfrontal winds from the northern quadrants are from the Arctic cold and dry air mass. As the cold front moves from the northwest to the area, the wind direction changes in an inertial oscillation fashion: southerly, southwesterly, northerly, and northeasterly (i.e., clockwise).

Prior to the passage of a cold front during the prefrontal phase, there is usually a reduction of outward flow from the bay, or a development or increase of an inward flow into the bay. As the cold front passes the area, a strong outward flow develops, producing the maximum outward subtidal flow (Fig. 5). This is the frontal phase. After the passage of the front (the postfrontal phase), flows reverse direction and reduce in magnitude. When these three phases are put together, the entire process typically produces roughly an asymmetric "M"- or "V"-shaped subtidal flow time series. The three-phase subtidal flow variation is a typical response to the change of wind regimes during a frontal passage event.

The 2013/14 data (Fig. 5a) show that the largest subtidal outward flow occurs at the CF station. CB has the second largest outward flow, followed by PA and BP in that order. The 2014/15 data (Fig. 5c) show that the largest outward flow occurs at CM (no data during 2013/14), followed by $\mathrm{CF}, \mathrm{CB}$, and $\mathrm{BP}$ (PA did not have valid data during this period). At times, the outward flows at $\mathrm{CF}$ and $\mathrm{CB}$ are concurrent with inward flows at PA and BP. These exchange flows usually occur at the prefrontal phase.

\section{e. Correlation}

The air pressure is not correlated with the subtidal flow (the correlation coefficient ranges from -0.1 to -0.35 ).
With a time shift, however, the correlation increases significantly (ranges from -0.4 to -0.59 ). The negative sign indicates that the drop of air pressure is correlated with an outward flow. The time shift is about 0.78 0.98 days (the mean values for 2013/14 and 2014/15 datasets, respectively; Tables 2 and 3). This time lag can be explained by the fact that the maximum northerly winds usually follow the frontal passage. At the lowest air pressure (when the front is passing the area), there is a change in wind direction before the strong northerly winds (Fig. 6). The lag is caused by the movement of the front, which depends on the speed at which the weather system moves.

The north wind is positively correlated with the subtidal flow. The averaged correlation value between north wind and subtidal flow is 0.65 for the first dataset and 0.57 for the second (Tables 2 and 3). With a time shift, the correlation increases significantly (ranges between 0.69 and 0.82 for the first dataset with an averaged time shift of 0.32 days and between 0.51 and 0.77 for the second dataset with an averaged time shift of 0.36 days). Again, since it takes some time for the flow to respond to the wind, a time lag is expected. The east wind is less correlated with the subtidal along-channel velocity (Tables 2 and 3). The time shift increases the correlation coefficient (e.g., up to 0.42 and 0.33 for the second dataset for CM and $\mathrm{CF}$, respectively), but the improvement is less significant.

\section{f. Coherence}

The MSC shows results (Fig. 7) in the frequency domain consistent with the correlation analysis. Tables 4 and 5 provide the results averaged over all frequencies as well as those over just the "weather band" (3-7 days in period or $0.14-0.33 \mathrm{cpd}$ in frequency), which is 
TABLE 3. Lagged correlation: time series 2.

\begin{tabular}{|c|c|c|c|c|c|c|}
\hline \multirow{2}{*}{$\frac{\text { Forcing }}{\text { Air pressure }}$} & \multirow{2}{*}{$\frac{\text { Response (subtidal flow) }}{\text { CF }}$} & \multirow{2}{*}{$\begin{array}{l}\text { No lag } \\
-0.170\end{array}$} & \multirow{2}{*}{$\begin{array}{c}\text { Lagged max } \\
-0.533\end{array}$} & \multicolumn{2}{|c|}{$95 \%$ confidence interval } & \multirow{2}{*}{$\frac{\text { Lag (days) }}{0.969}$} \\
\hline & & & & -0.203 & -0.863 & \\
\hline & $\mathrm{CB}$ & -0.082 & -0.407 & -0.107 & -0.707 & 0.993 \\
\hline & $\mathrm{CM}$ & -0.298 & -0.567 & -0.197 & -0.937 & 0.792 \\
\hline & $\mathrm{BP}$ & 0.073 & -0.397 & -0.097 & -0.697 & 1.149 \\
\hline Average & & -0.183 & -0.467 & -0.151 & -0.801 & 0.976 \\
\hline \multirow[t]{4}{*}{ North wind } & $\mathrm{CF}$ & 0.656 & 0.747 & 0.3660 & 1.000 & 0.347 \\
\hline & $\mathrm{CB}$ & 0.526 & 0.624 & 0.2720 & 0.976 & 0.385 \\
\hline & $\mathrm{CM}$ & 0.709 & 0.773 & 0.3620 & 1.000 & 0.267 \\
\hline & $\mathrm{BP}$ & 0.374 & 0.508 & 0.2270 & 0.789 & 0.434 \\
\hline Average & & 0.566 & 0.663 & 0.307 & 0.941 & 0.358 \\
\hline \multirow[t]{4}{*}{ East wind } & $\mathrm{CF}$ & -0.025 & 0.333 & 0.142 & 0.5240 & 1.431 \\
\hline & $\mathrm{CB}$ & -0.058 & 0.237 & 0.125 & 0.3490 & 1.517 \\
\hline & $\mathrm{CM}$ & 0.164 & 0.415 & 0.144 & 0.6860 & 1.118 \\
\hline & BP & -0.522 & 0.234 & 0.121 & 0.3470 & 2.549 \\
\hline Average & & -0.110 & 0.305 & 0.133 & 0.476 & 1.654 \\
\hline
\end{tabular}

equivalent to the range of the period for most of the cold front recurrence (3-7 days). Since the cutoff frequency for the low-pass filtering is $0.6 \mathrm{cpd}$, only the results lower than this frequency are meaningful (Fig. 7).

Using the first dataset as an example, the MSC between air pressure and low-pass filtered (subtidal)

(a)

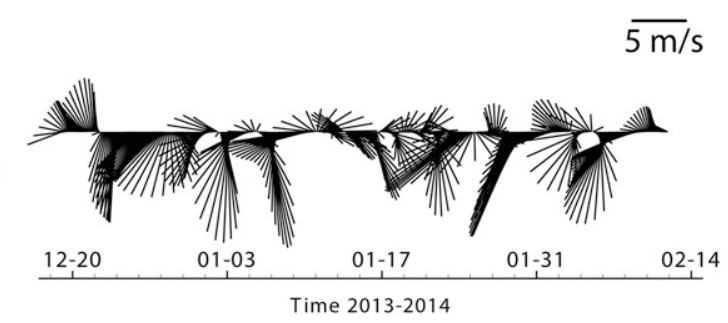

(b)
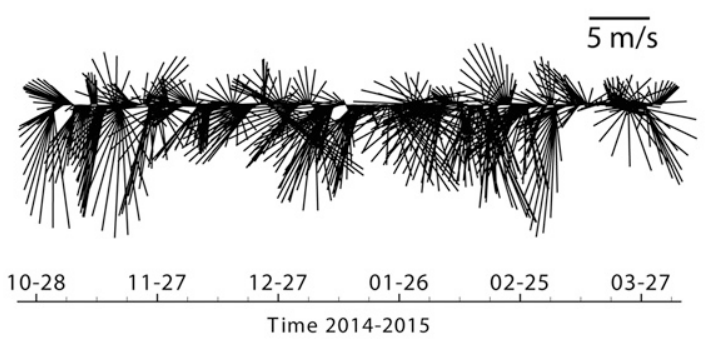

(c)

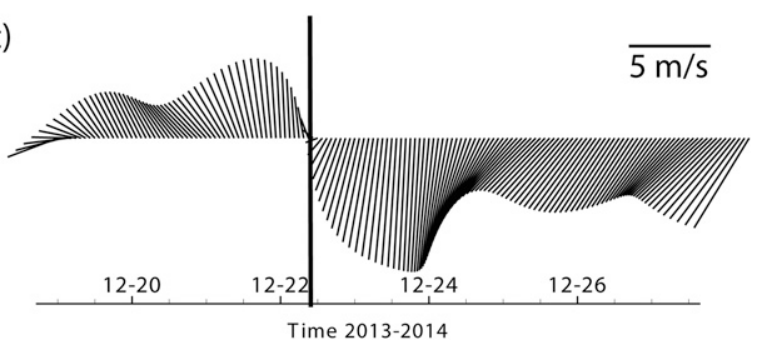

FIG. 6. Wind vector time series for the (a) 2013/14 and (b) 2014/ 15 time periods, respectively. (c) A zoomed-in example of typical cold front wind variations; the vertical bar denotes the timing of a cold front. along-channel flow (Fig. 7a) is small at low frequencies but has larger values (above 0.5 and up to $\sim 0.9$ ) at higher frequencies except at about $f=0.45 \mathrm{cpd}$. The variation of this MSC among different locations ranges between 0.474 (station at $\mathrm{CB}$ ) and 0.570 (station at PA). The average value of this MSC is 0.527 with an averaged standard deviation of 0.198 (Table 4). For the weather band only, the MSC ranges between 0.634 (CF) and 0.751 (PA) for different stations, with an average value of 0.667 . The standard deviation of MSC for the weather band is much reduced, which ranges between 0.045 (CB) and 0.095 (PA) with an average of 0.071 (Table 4). This means that within the weather band the two variables are strongly correlated at all frequencies. In other words, the variation of flow within this band $(0.14-0.33 \mathrm{cpd}$ or 3-7 days) is contributed mostly by the cold frontdominated weather.

The MSC between the north wind and low-pass filtered along-channel flow (Fig. 7b) is much larger, except for the BP data. The mean standard deviation of this MSC for each location ranges between 0.083 (PA) and 0.175 (BP; Table 4). The overall mean values of this MSC among different locations are all high (ranging between 0.677 at BP and 0.792 at CF; Table 4), with an averaged value of 0.738 , with an averaged standard deviation among different stations of 0.131 (Table 4). For the weather band only, this MSC ranges between 0.479 (BP) and 0.890 (CF) for different stations, with an average value of 0.733 . The standard deviation of this MSC for the weather band is also much reduced, which ranges between 0.025 (CF) and 0.149 (BP) with an average of 0.072 (Table 4). It is unexpected that the BP station has a much lower MSC for the weather band. This may be due to the fact that the ADCP at BP was deployed at the eastern end, which 

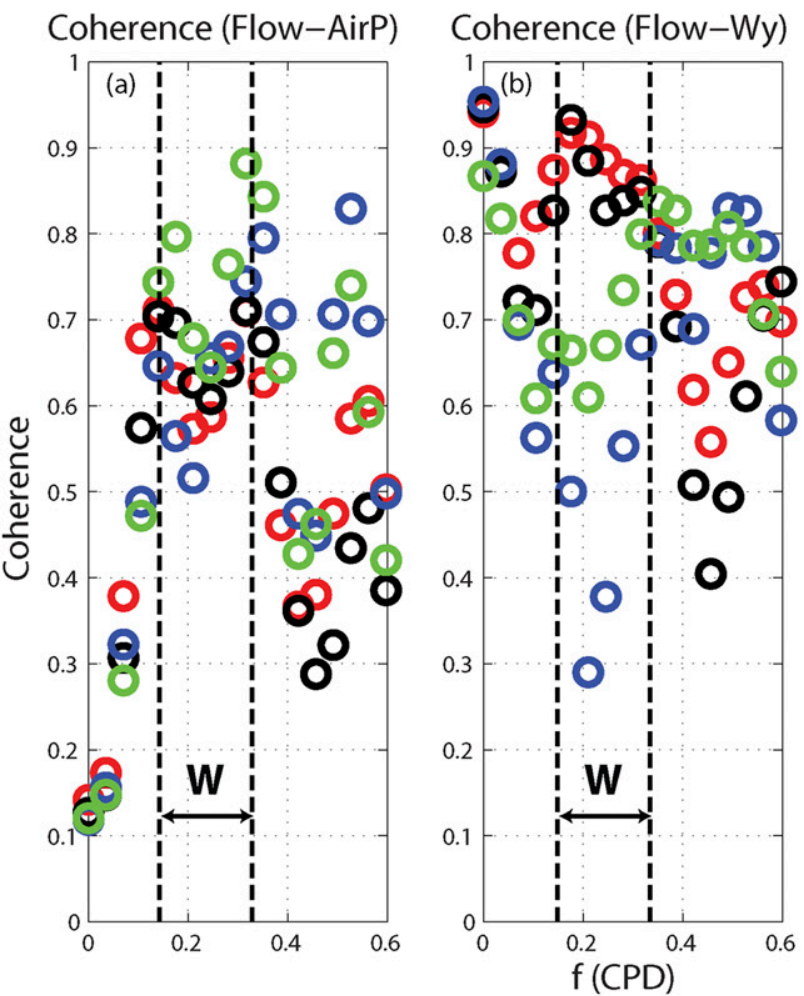

Coherence (Flow-Wx)

Coherence (Flow-AirP)

Coherence (Flow-Wy)
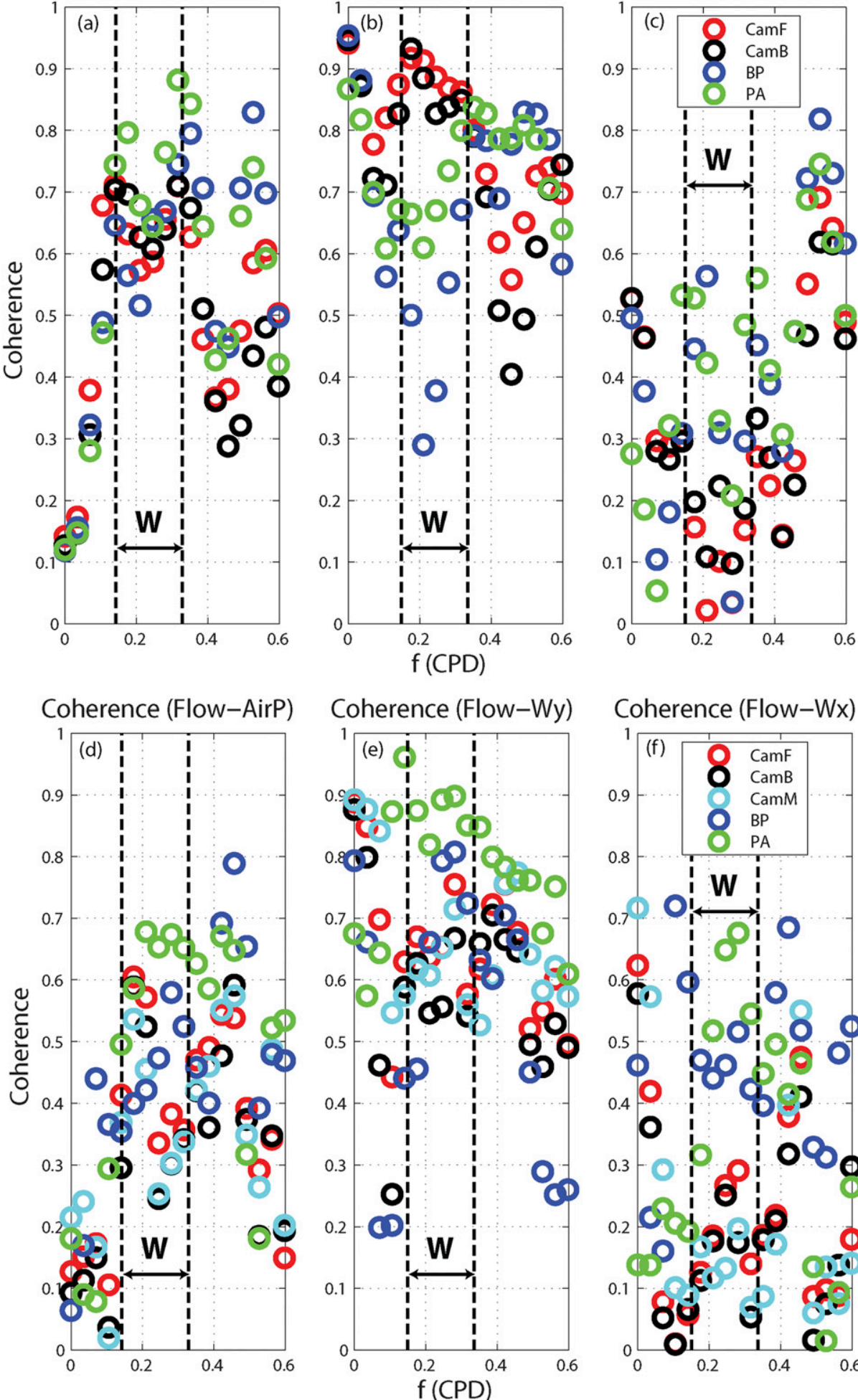

Coherence (Flow-Wx)

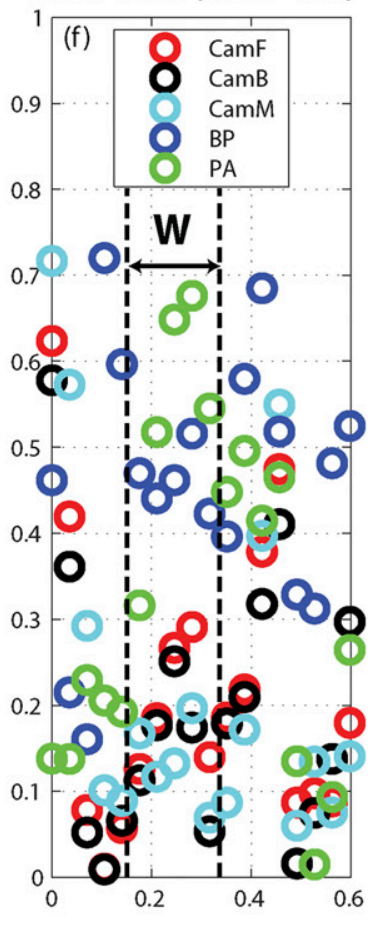

FIG. 7. Magnitude squared coherence function between the subtidal (or low-pass filtered) alongchannel flow velocity and (a) air pressure, (b) north wind, or (c) east wind for the 2013/14 data. (d)-(f) As in (a)-(c), but for the 2014/15 data. The colors of the circles indicate the stations. The vertical dashed lines and "W" indicate the "weather band" $(0.14-0.33 \mathrm{cpd})$. 
TABLE 4. Mean coherence of 40-h low-pass flow with forcing: time series 1.

\begin{tabular}{|c|c|c|c|c|c|c|c|c|c|}
\hline \multirow{3}{*}{$\frac{\text { Forcing }}{\text { Air pressure }}$} & \multirow{3}{*}{$\begin{array}{c}\begin{array}{c}\text { Response } \\
\text { (subtidal flow) }\end{array} \\
\mathrm{CF}\end{array}$} & \multicolumn{4}{|c|}{ All band } & \multicolumn{4}{|c|}{ Weather band $(0.14-0.33 \mathrm{cpd})$} \\
\hline & & \multirow{2}{*}{$\frac{\text { Mean }}{0.511}$} & \multirow{2}{*}{$\begin{array}{c}\begin{array}{c}\text { Standard } \\
\text { deviation }\end{array} \\
0.170\end{array}$} & \multicolumn{2}{|c|}{$\begin{array}{c}95 \% \text { confidence } \\
\text { interval }\end{array}$} & \multirow{2}{*}{$\begin{array}{c}\text { Mean } \\
0.634\end{array}$} & \multirow{2}{*}{$\begin{array}{c}\begin{array}{c}\text { Standard } \\
\text { deviation }\end{array} \\
0.055\end{array}$} & \multicolumn{2}{|c|}{$\begin{array}{c}95 \% \text { confidence } \\
\text { interval }\end{array}$} \\
\hline & & & & 0.178 & 0.844 & & & 0.526 & 0.7418 \\
\hline & $\mathrm{CB}$ & 0.474 & 0.190 & 0.102 & 0.846 & 0.657 & 0.045 & 0.569 & 0.7452 \\
\hline & BP & 0.554 & 0.203 & 0.156 & 0.952 & 0.628 & 0.090 & 0.452 & 0.8044 \\
\hline & PA & 0.570 & 0.228 & 0.123 & 1.000 & 0.751 & 0.095 & 0.565 & 0.9372 \\
\hline Average & & 0.527 & 0.198 & 0.139 & 0.915 & 0.667 & 0.071 & 0.528 & 0.8062 \\
\hline \multirow[t]{4}{*}{ North wind } & $\mathrm{CF}$ & 0.792 & 0.112 & 0.573 & 1.000 & 0.890 & 0.025 & 0.841 & 0.939 \\
\hline & $\mathrm{CB}$ & 0.742 & 0.155 & 0.438 & 1.000 & 0.866 & 0.043 & 0.782 & 0.950 \\
\hline & $\mathrm{BP}$ & 0.677 & 0.175 & 0.334 & 1.000 & 0.479 & 0.149 & 0.187 & 0.771 \\
\hline & $\mathrm{PA}$ & 0.740 & 0.083 & 0.577 & 0.903 & 0.696 & 0.073 & 0.553 & 0.839 \\
\hline Average & & 0.738 & 0.131 & 0.481 & 0.995 & 0.733 & 0.072 & 0.592 & 0.874 \\
\hline \multirow[t]{4}{*}{ East wind } & $\mathrm{CF}$ & 0.312 & 0.204 & 0.088 & 0.712 & 0.093 & 0.064 & 0.032 & 0.218 \\
\hline & $\mathrm{CB}$ & 0.321 & 0.166 & 0.004 & 0.646 & 0.163 & 0.056 & 0.053 & 0.273 \\
\hline & BP & 0.422 & 0.215 & 0.001 & 0.843 & 0.330 & 0.198 & 0.058 & 0.718 \\
\hline & $\mathrm{PA}$ & 0.425 & 0.182 & 0.068 & 0.782 & 0.395 & 0.128 & 0.144 & 0.646 \\
\hline Average & & 0.370 & 0.191 & 0.004 & 0.744 & 0.245 & 0.111 & 0.027 & 0.463 \\
\hline
\end{tabular}

is a few hundred meters from the center of the main channel and where the flow was affected by the shallow water, which may not represent the major flow through the channel. Other than the BP station, this MSC indicates that within the weather band the two variables are much more correlated at all frequencies.

The MSC between the east wind and low-pass filtered along-channel flow (Fig. 7c) is smaller and more variable, ranging between almost 0 and a little over 0.8 . The mean value of this MSC for each station has relatively low values from $0.312(\mathrm{CF})$ to 0.425 (PA), with an average of 0.370 (Table 4 ). The mean standard deviation of this MSC for each location ranges between 0.166 (CB) and $0.215(\mathrm{BP})$. The second dataset has similar results for the MSC (Figs. 7d,e,f).

\section{g. Model results}

\section{1) SKILL ASSESSMENT}

The FVCOM skill scores are 0.7 (Fig. 8a) and 0.67 (Fig. 8c) for the water level and along-channel velocity, respectively. These values are usually considered as "excellent" for the model performance (Wu et al. 2011). The low-pass filtered model results for water level (Fig. 8b) and low-pass filtered model results for along-channel velocity (Fig. 8d) have skill scores of 0.51 and 0.60 , respectively, which

TABLE 5. Mean coherence of 40-h low-pass flow with forcing: time series 2.

\begin{tabular}{|c|c|c|c|c|c|c|c|c|c|}
\hline \multirow{3}{*}{$\frac{\text { Forcing }}{\text { Air pressure }}$} & \multirow{3}{*}{$\begin{array}{c}\begin{array}{c}\text { Response } \\
\text { (subtidal flow) }\end{array} \\
\mathrm{CF}\end{array}$} & \multicolumn{4}{|c|}{ All band } & \multicolumn{4}{|c|}{ Weather band $(0.14-0.33 \mathrm{cpd})$} \\
\hline & & \multirow{2}{*}{$\begin{array}{c}\text { Mean } \\
0.358\end{array}$} & \multirow{2}{*}{$\begin{array}{c}\begin{array}{c}\text { Standard } \\
\text { deviation }\end{array} \\
0.163\end{array}$} & \multicolumn{2}{|c|}{$\begin{array}{l}95 \% \text { confidence } \\
\text { interval }\end{array}$} & \multirow{2}{*}{$\frac{\text { Mean }}{0.450}$} & \multirow{2}{*}{$\begin{array}{c}\begin{array}{c}\text { Standard } \\
\text { deviation }\end{array} \\
0.128\end{array}$} & \multicolumn{2}{|c|}{$\begin{array}{c}95 \% \text { confidence } \\
\text { interval }\end{array}$} \\
\hline & & & & 0.039 & 0.678 & & & 0.199 & 0.701 \\
\hline & $\mathrm{CB}$ & 0.313 & 0.167 & 0.014 & 0.640 & 0.400 & 0.149 & 0.108 & 0.692 \\
\hline & $\mathrm{CM}$ & 0.345 & 0.151 & 0.049 & 0.641 & 0.377 & 0.116 & 0.150 & 0.604 \\
\hline & $\mathrm{BP}$ & 0.452 & 0.170 & 0.119 & 0.785 & 0.480 & 0.074 & 0.335 & 0.625 \\
\hline Average & & 0.367 & 0.163 & 0.048 & 0.686 & 0.427 & 0.117 & 0.198 & 0.656 \\
\hline \multirow[t]{4}{*}{ North wind } & $\mathrm{CF}$ & 0.652 & 0.116 & 0.425 & 0.879 & 0.658 & 0.064 & 0.533 & 0.783 \\
\hline & $\mathrm{CB}$ & 0.587 & 0.140 & 0.313 & 0.861 & 0.588 & 0.057 & 0.476 & 0.700 \\
\hline & $\mathrm{CM}$ & 0.665 & 0.116 & 0.438 & 0.892 & 0.630 & 0.058 & 0.516 & 0.744 \\
\hline & $\mathrm{BP}$ & 0.533 & 0.217 & 0.108 & 0.958 & 0.688 & 0.143 & 0.408 & 0.968 \\
\hline Average & & 0.609 & 0.147 & 0.321 & 0.897 & 0.641 & 0.081 & 0.482 & 0.800 \\
\hline \multirow[t]{4}{*}{ East wind } & $\mathrm{CF}$ & 0.217 & 0.165 & 0.106 & 0.540 & 0.202 & 0.074 & 0.057 & 0.347 \\
\hline & $\mathrm{CB}$ & 0.193 & 0.153 & 0.107 & 0.493 & 0.154 & 0.075 & 0.007 & 0.301 \\
\hline & $\mathrm{CM}$ & 0.226 & 0.199 & 0.164 & 0.616 & 0.137 & 0.049 & 0.041 & 0.233 \\
\hline & BP & 0.461 & 0.145 & 0.177 & 0.745 & 0.462 & 0.035 & 0.393 & 0.531 \\
\hline Average & & 0.274 & 0.166 & 0.051 & 0.599 & 0.239 & 0.058 & 0.125 & 0.353 \\
\hline
\end{tabular}



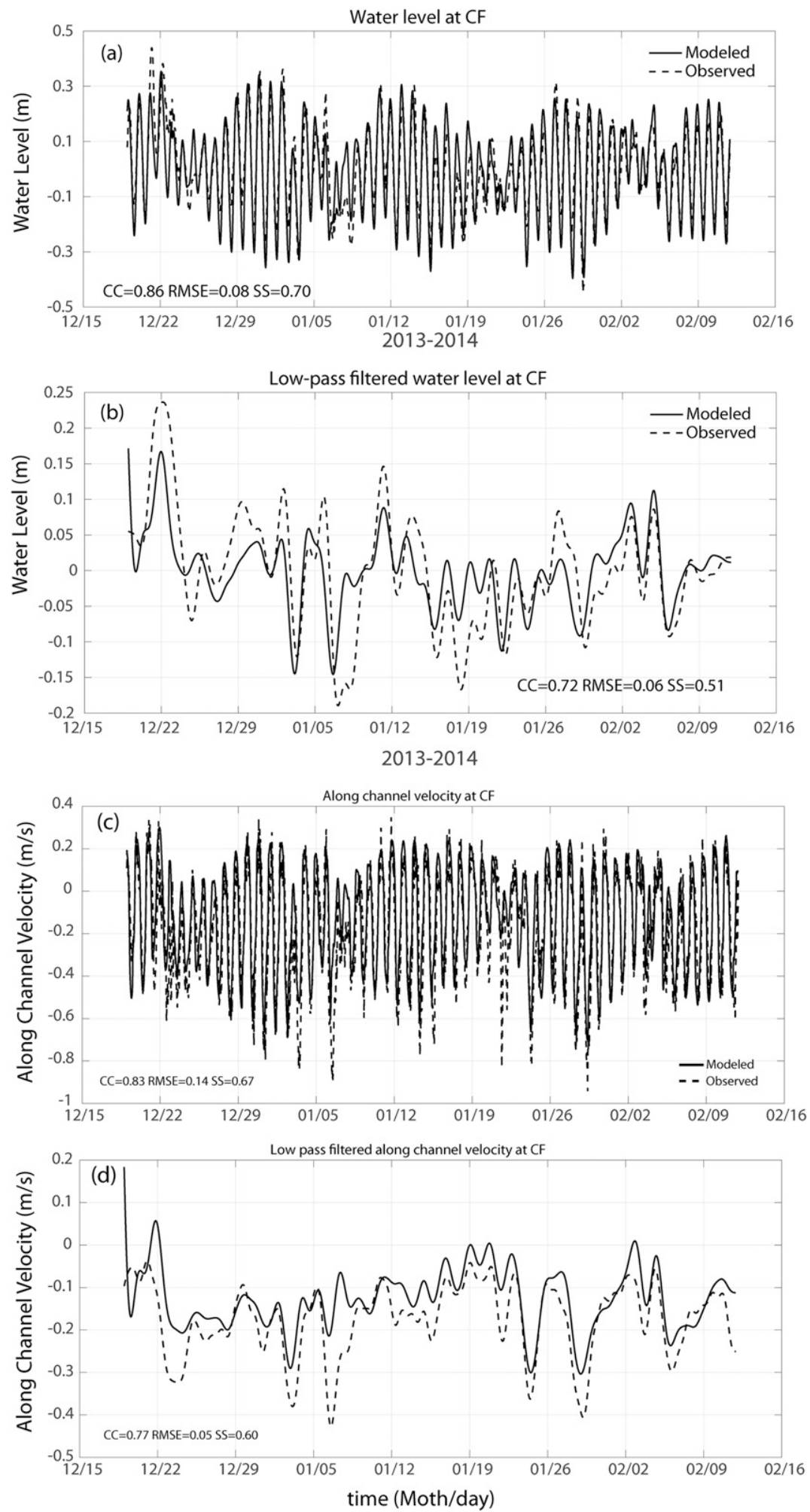

FIG. 8. Model-data comparison for water level at the CF station: (a) time series comparison and (b) subtidal time series comparison for the 2013/14 data. (c),(d) As in (a) and (b), but for the 2014/15 data. The water-level data were from the NOAA station at Grand Isle. The correlation coefficient (CC), root-mean-square error (RMSE), and skill score (SS) are shown. 


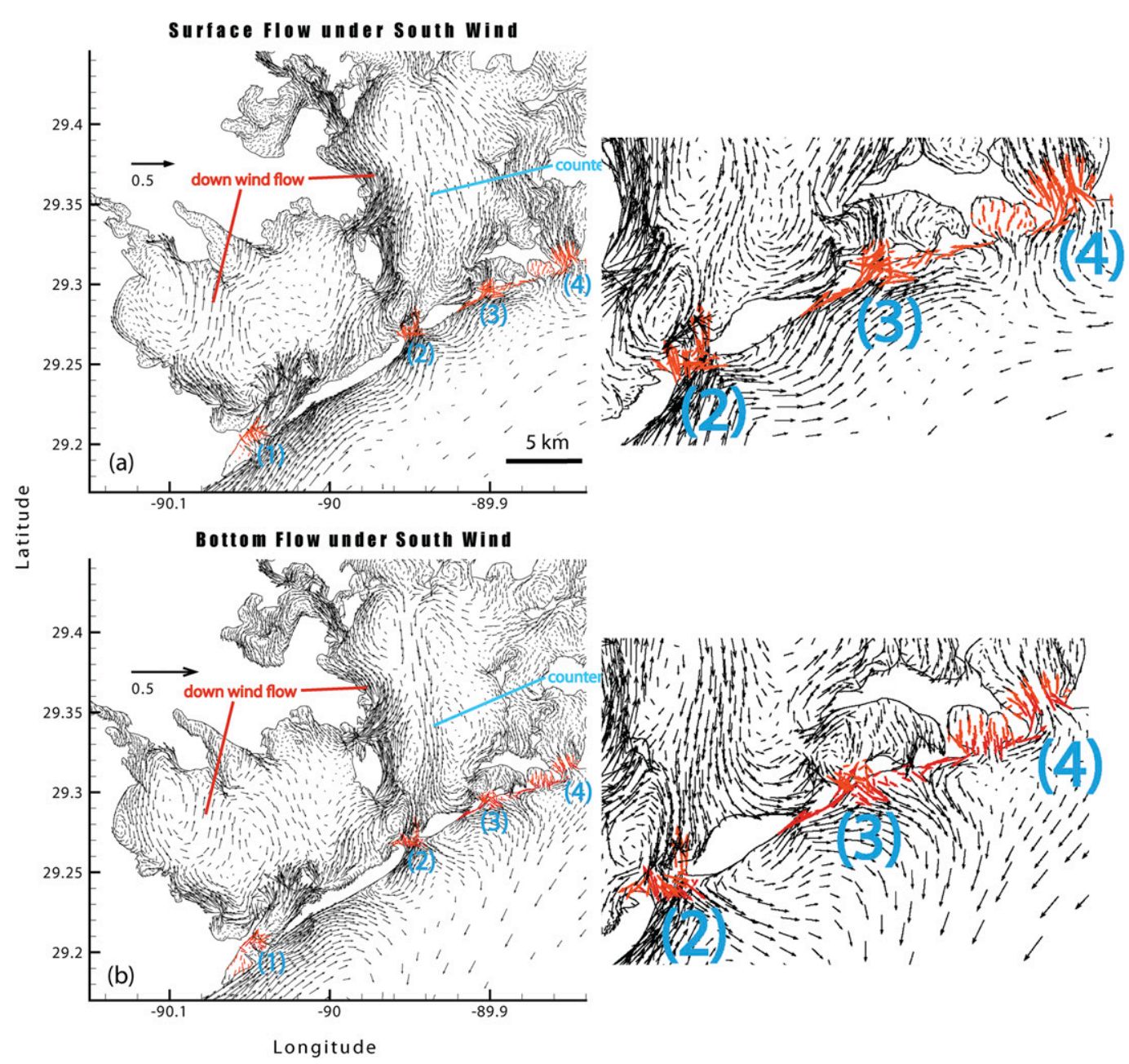

FIG. 9. (left) Velocity vectors under south wind at (a) surface and (b) bottom. Red arrows are used to show flows at the inlets. (right) Zoomed-in flows at the three inlets.

indicate a "very good" performance of the model (Wu et al. 2011).

\section{2) Circulations And FluX AT inlets}

Here we choose the flow vector fields from the FVCOM output at four different times corresponding to the maximum south, north, west, and east winds, respectively, to examine the wind-driven flows. The time instances are 0000 UTC 12 December 2013 and 7, 10, and 26 January 2014 for the south, north, west, and east winds, respectively. The wind speeds for these times are $7,13,8$, and $5 \mathrm{~m} \mathrm{~s}^{-1}$, respectively. Common features of these vector maps include the downwind flows over shallow shoals and counterwind flows in deeper waters especially the central deep channel (cf. the bathymetry in Fig. 2b with Figs. 9-12).

During southerly wind (Fig. 9), the flows at inlets 1 (Caminada Pass) and 4 (Quatre Bayou Pass) are into the bay, while inlets 2 (Barataria Pass) and 3 (Pass Abel) have some outward flow through the channels, consistent with $\mathrm{Li}$ (2013); that is, wind-driven flows in a multiple-inlet system tend to be downwind in shallow inlets and counterwind in deeper inlets. The return flows at bottom are even more pronounced (Fig. 9b).

During the strong northerly wind with a maximum $13 \mathrm{~m} \mathrm{~s}^{-1}$ (Fig. 10), the surface flows (Fig. 10a) in all inlets are outward. The bottom waters (Fig. 10b), however, have some counterwind return flow, although conditions at the bottom of inlet 1 are complicated by the $90^{\circ}$ turn of the channel.

During westerly wind (Fig. 11), the surface flows (Fig. 11a) in inlets 2, 3, and 4 are all outward, while inlet 1 has some inward flows. The bottom water (Fig. 11b) at inlet 4 is outward; while at inlets 2 and 3 the flows are mostly outward, but with some inward flows on the sides; and inlet 1 has some inward flows as well on the western side. This is similar to the scenario described in $\mathrm{Li}$ (2013) of wind with an offshore or onshore component, in 


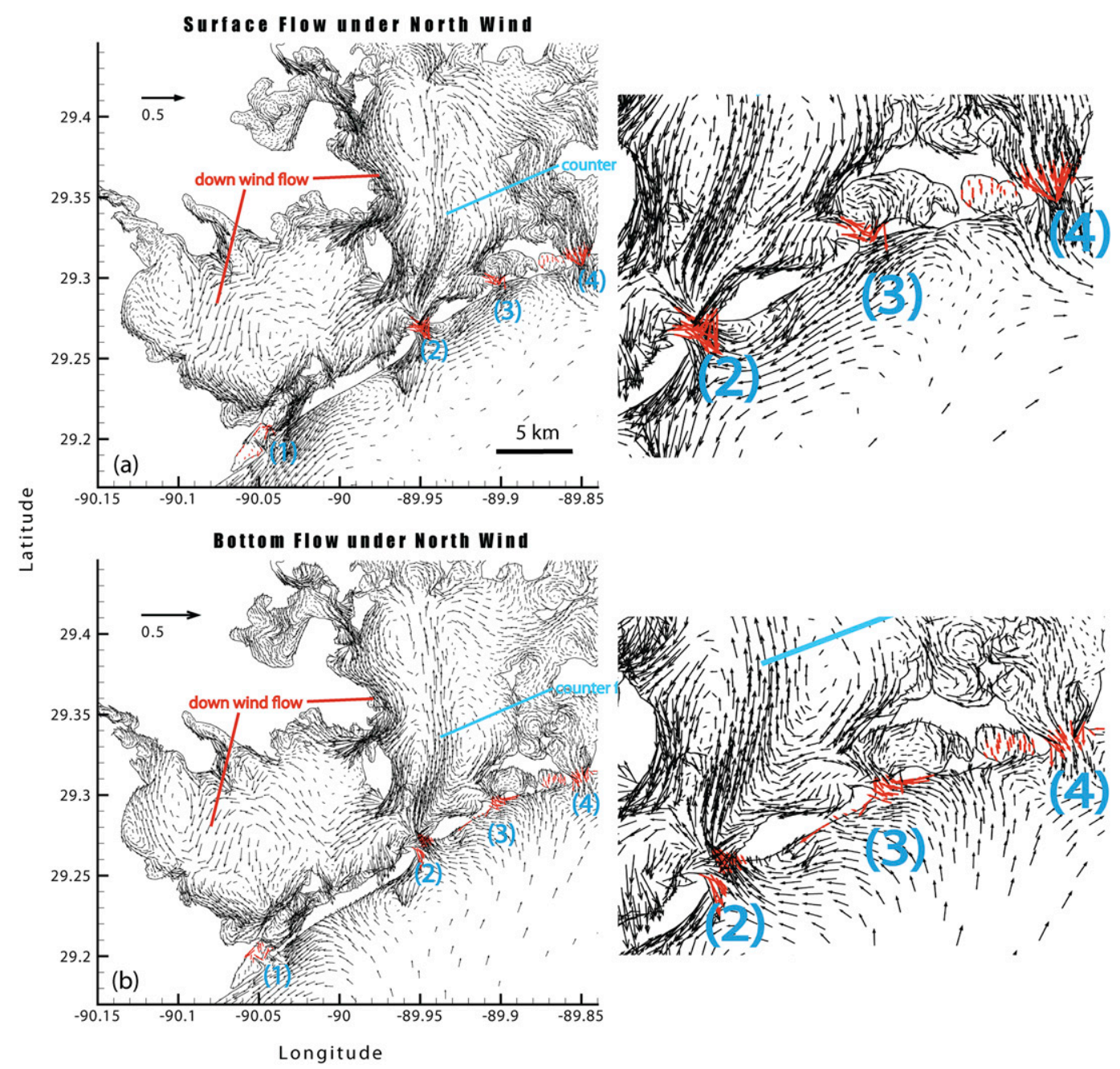

FIG. 10. (left) Velocity vectors under north wind at (a) surface and (b) bottom. Red arrows are used to show flows at the inlets. (right) Zoomed-in flows at the three inlets.

which the upstream inlet tends to have inward flows while the downstream inlet tends to have outward flows.

During easterly wind (Fig. 12), the surface flows (Fig. 12a) in inlets 3 and 4 are all inward, while inlet 1 has outward flows. The bottom waters (Fig. 12b) at the upwind inlets 3 and 4 have inward flows; while inlets 1 and 2 have outward flows. This is again consistent with $\mathrm{Li}$ (2013) of an along-shelf wind with an offshore or inshore component, in which the upwind inlet tends to have inward flows while the downwind inlet tends to have outward flows.

\section{3) INTEGRATED TIDAL TRANSPORTS THROUGH THE INLETS}

The 3D field of flow vectors from the FVCOM model is used to calculate the cross-sectional total transport of water for the entire simulation period. The results are a set of time series of scalars at each inlet, with positive values defined as inward and negative values as outward transport. It is found that the relative ratios of tidal transports among the four major inlets are quite persistent over time. About $9.63 \%, 56.65 \%, 21.46 \%$, and $12.25 \%$ of the total transports are through Caminada Pass, Barataria Pass, Pass Abel, and Quatre Bayou Pass, respectively. Past studies with single-day crude observations have determined the transports to be $13 \%, 66 \%$, $3 \%$, and 18\% (Marmer 1948), respectively. These are somewhat different results. However, the values for three of the passes are quite close to the present-day estimate. Transport through Pass Abel seems to have changed greatly, which is consistent with our recent observations of the fast evolution of the inlet. In general, validated model results integrated over the entire cross section should have a more reliable estimate. In addition, land loss and migration of barrier islands can 


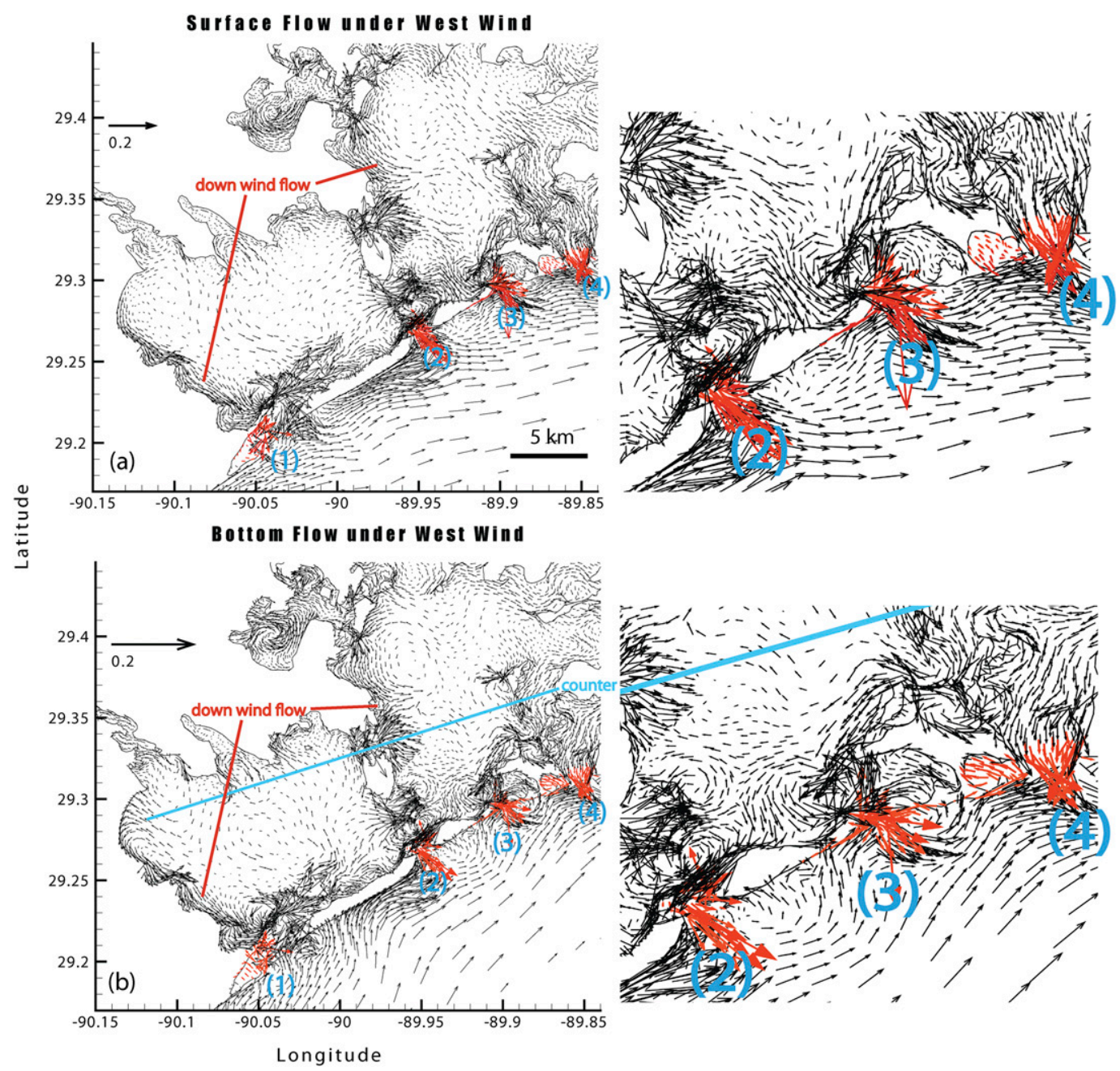

FIG. 11. (left) Velocity vectors under west wind at (a) surface and (b) bottom. Red arrows are used to show flows at the inlets. (right) Zoomed-in flows at the three inlets.

change the cross-sectional area (FitzGerald et al. 2008), tidal prism, and therefore transport values and relative ratios among different inlets over time.

\section{4) INTEGRATED SUBTIDAL TRANSPORTS THROUGH THE INLETS}

With the 40-h low-pass filtering, the subtidal transports through the inlets are found to vary substantially, contrary to the more robust relative ratios for tidal transports. The ratios of subtidal transports through these inlets are estimated to have a mean and standard deviation of $18.23 \% \pm 13.33 \%, 34.51 \% \pm 18.10 \%, 30.89 \% \pm 15.86 \%$, and $16.37 \% \pm 9.36 \%$ for Caminada Pass, Barataria Pass, Pass Abel, and Quatre Bayou Pass, respectively. At the maximum, Caminada Pass once had $60.70 \%$ of the total transport; while Barataria Pass, Pass Abel, and Quatre Bayou Pass had $92.42 \%, 83.66 \%$, and $47.06 \%$ of the total transport at the maximum, respectively.
This large variation in subtidal transport ratios is because of the sensitivity of transport (through the multiple inlets) to the direction, duration, and magnitude of the wind vector. Under northerly winds during a cold front, all four inlets can have outward transport (Figs. 13a,b, indicated by lines at A, D, and F; Figs. 13c,d at lines A, B, D, and after E). Similarly, with southerly winds, all four or at least three of the inlets may have inward transport (Figs. 13a,b, indicated by the line at B; Figs. 13c,d before line A; Figs. 13e,f between lines A and $\mathrm{B}$ and at $\mathrm{H}$; Figs. $13 \mathrm{~g}$,h between lines $\mathrm{C}$ and $\mathrm{F}$ ). When the wind relaxes, the transport through at least the middle two inlets (Barataria Pass and Pass Abel) often experience reversed transport (Figs. 13a,b, lines E and G; Figs. 13c,d, lines $\mathrm{C}$ and E; Figs. 13e,f, lines D and F; Figs. 13g,h, lines $\mathrm{H}$ and I). By wind relaxation, we meant that the wind magnitude reduces, which often is accompanied by a change in wind direction. 


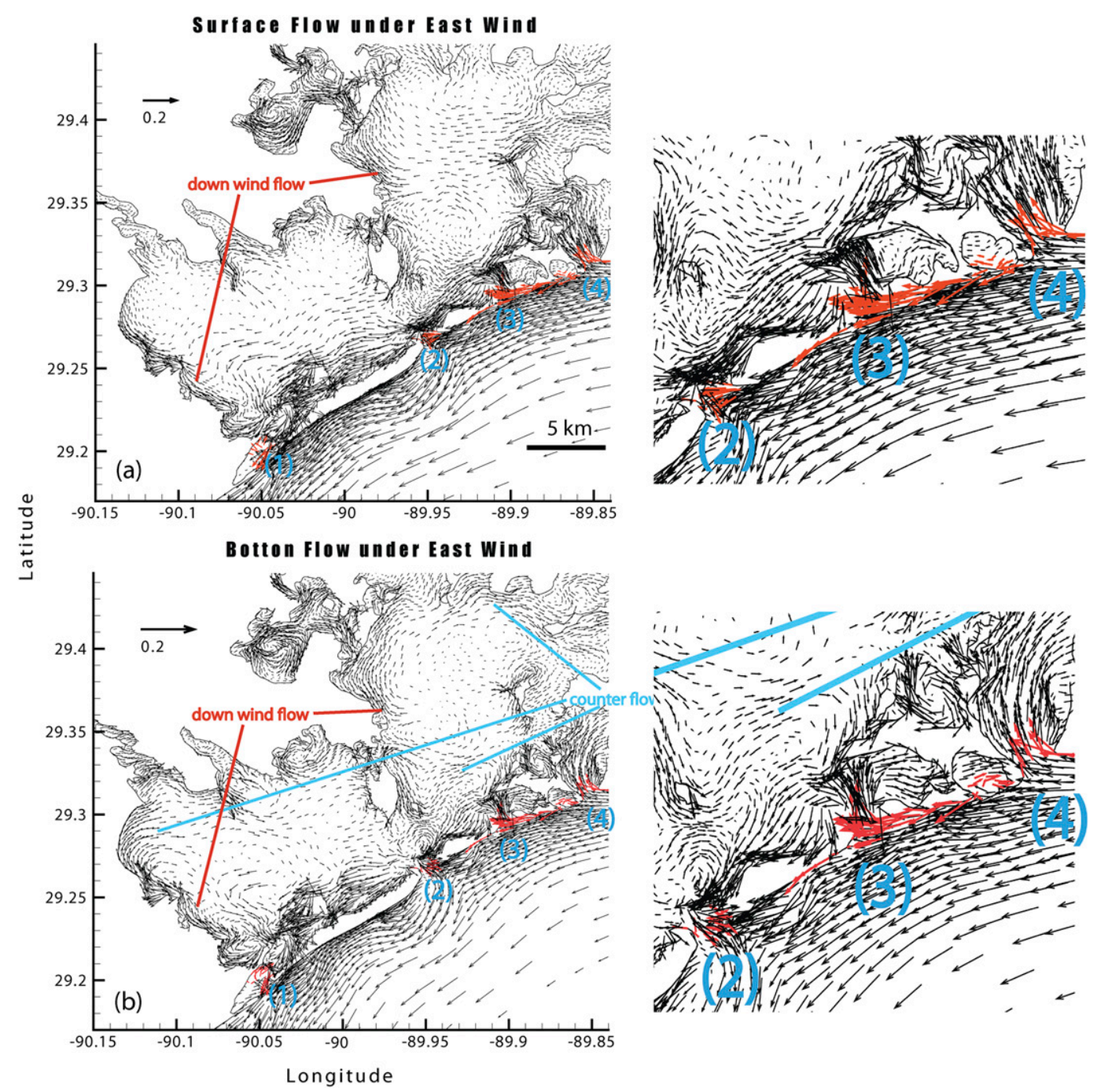

FIG. 12. (left) Velocity vectors under east wind at (a) surface and (b) bottom. Red arrows are used to show flows at the inlets. (right) Zoomed-in flows at the three inlets.

\section{h. Mode analysis with EOF}

The first four EOF modes carry $\sim 45 \%, 41 \%, 13 \%$, and $1 \%$ variabilities of the data, respectively. Therefore, we will only discuss the first three modes. The three eigenvectors are, respectively (Fig. 14),

$\mathbf{E}_{1}=\left(\begin{array}{c}0.22 \\ 0.59 \\ 0.47 \\ 0.32 \\ -0.35 \\ 0.35\end{array}\right), \quad \mathbf{E}_{2}=\left(\begin{array}{c}0.25 \\ -0.44 \\ -0.10 \\ 0.10 \\ 0.21 \\ 0.82\end{array}\right), \quad \mathbf{E}_{3}=\left(\begin{array}{c}0.23 \\ 0.56 \\ -0.15 \\ -0.19 \\ 0.75 \\ 0.05\end{array}\right)$.

The first mode depicts a pattern with all-in transport at all four inlets under southeasterly wind and all-out transport under northwesterly winds (Figs. 14a,b). The second mode (Figs. 14c,d) depicts a pattern under southsouthwesterly wind that pushes the transport inward at the easternmost and westernmost inlets along the shallow shoals of the bay with counterwind transport through the middle two inlets (Barataria Pass and Pass Abel); under north-northeasterly wind, the transport at the easternmost and westernmost inlets along the shallow shoals of the bay is outward and that through the middle two inlets are inward. This mode tends to occur at the wind-relaxation periods. The third mode (Figs. 14e,f) shows inward transport through the Caminada Pass and Barataria Pass with outward transport through Pass Abel and Quatre Bayou Pass under wind from almost due south, and outward transport through the Caminada Pass and Barataria Pass but inward 


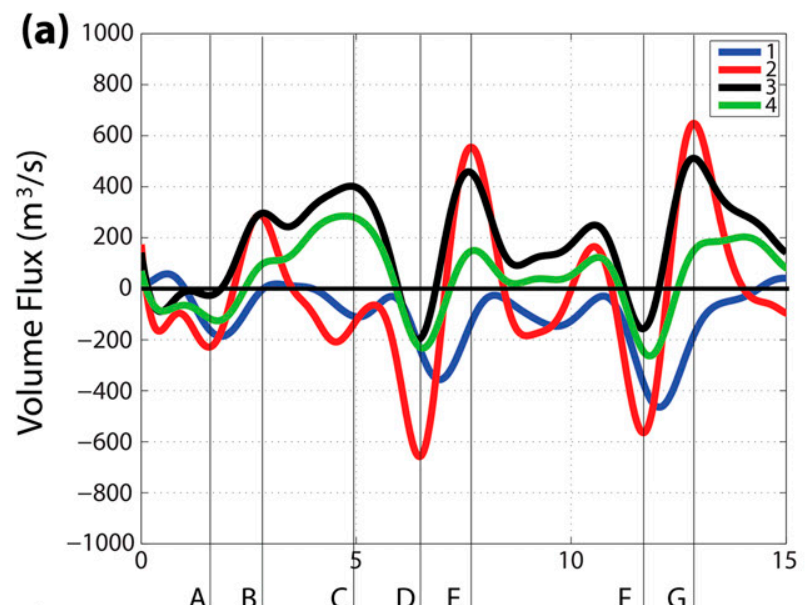

(b)
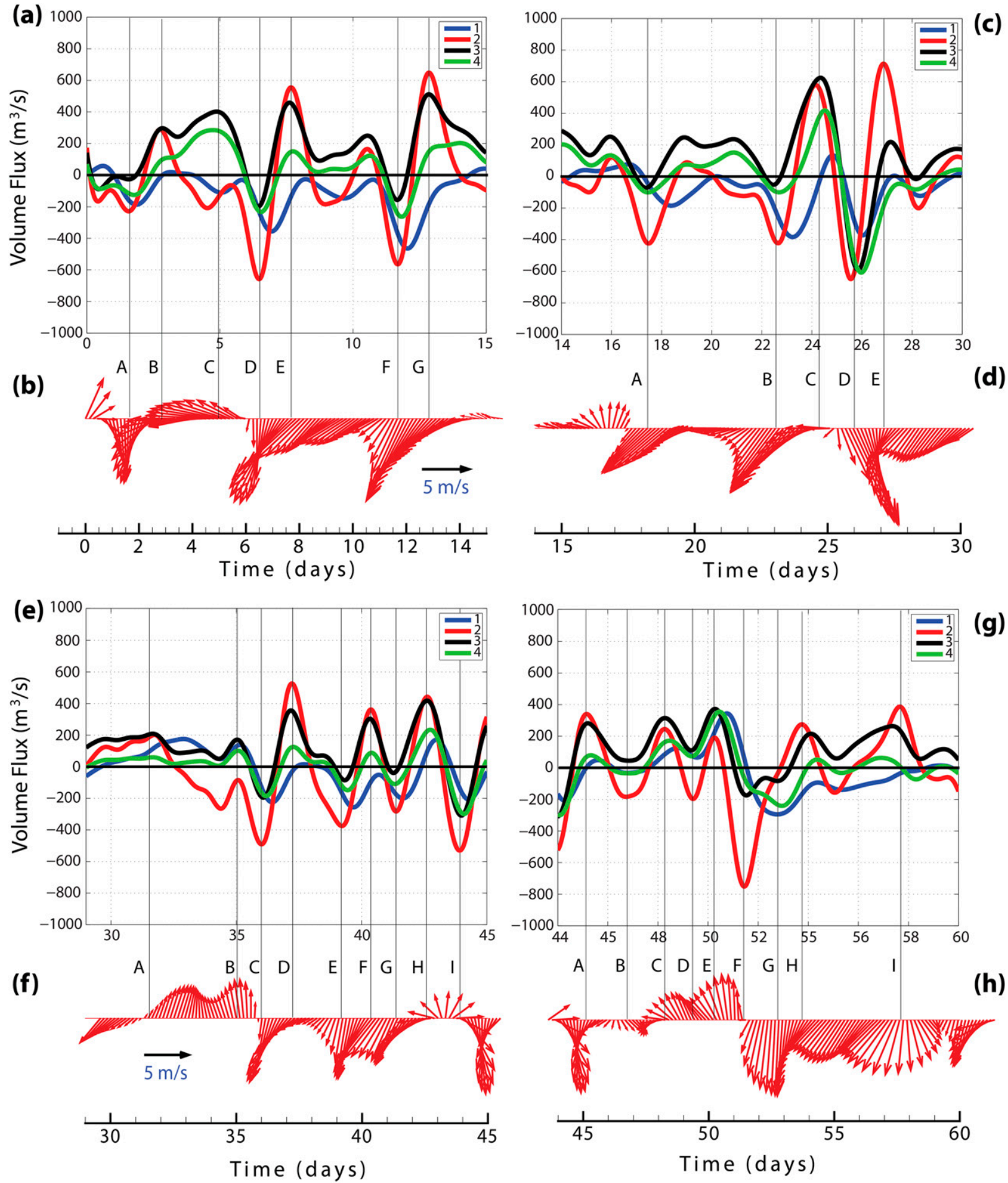

FIG. 13. (a),(c),(e),(g) FVCOM modeled subtidal volume flux through the 4 tidal inlets lined up with the (b),(d),(f),(h) lowpass filtered wind vector time series for the 2013/14 data. Each pair of panels, i.e., (a) and (b), is for 15 days. The blue, red, black, and green lines are for Caminada Pass, Barataria Pass, Pass Abel, and Quatre Bayou Pass, respectively. Time (days) starting from 1 Nov 2013. 

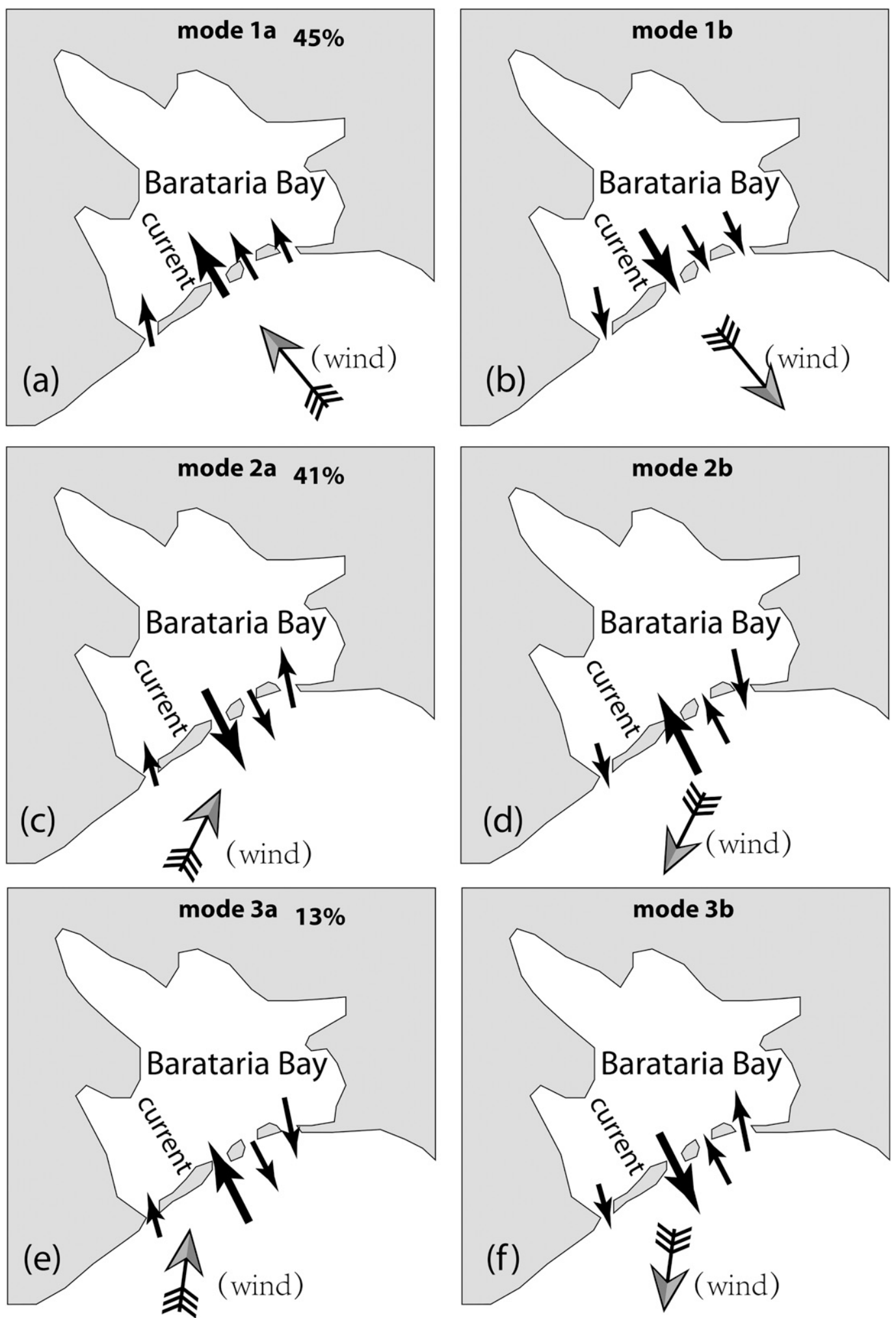

FIG. 14. The first three modes for the forcing-response joint EOF analysis: (a),(b) the first mode (with positive or negative coefficients); (c),(d) the second mode; and (e),(f) the third mode. 


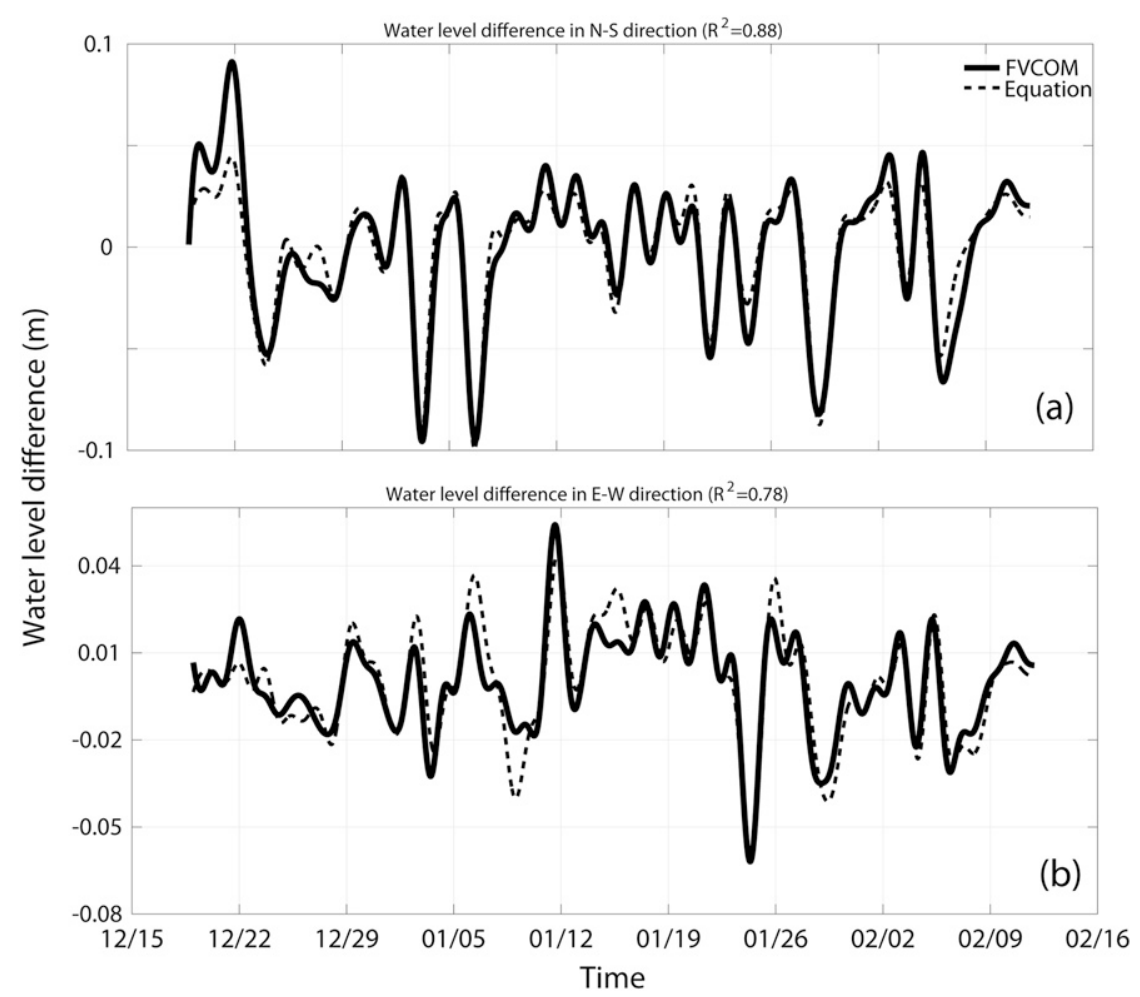

FIG. 15. Comparison of water-level difference between FVCOM output and the results from the quasi-steady-state equation in the (a) north-south direction and (b) east-west direction.

transport through Pass Abel and Quatre Bayou Pass under wind from almost due north.

The first two modes are shown in the earlier discussion in section $3 \mathrm{~g}$. The last mode is consistent with $\mathrm{Li}$ (2013) in which a numerical experiment concludes that wind-driven flows in a multiple-inlet system tends to have an inward transport through the upwind inlets and outward transport through the downwind inlets, when the wind vector has an acute angle with the coastline.

\section{Discussion}

\section{a. Quasi-steady state}

In a one-dimensional channel with a closed end at least in the downwind direction, and under a constant wind forcing, the steady-state force balance would be

$$
0=-g \frac{\partial \zeta}{\partial x}+\frac{\tau_{a x}}{\rho h}
$$

in which $\zeta, \tau_{a x}, \rho, h$, and $g$ are the water elevation from the mean sea level, wind stress component in the $x$ direction, water density, and water depth at equilibrium when there is no force, respectively. Wind stress in the $x$ direction can be calculated by $\tau_{a x}=\rho C_{D} u_{T} u$, where $u$ is the north or east wind components, $u_{T}$ is the wind speed, and $C_{D}$ is the bottom drag coefficient. If the wind varies in time or if the problem is not "one dimensional," or if the end is not fully closed, the above force balance would not hold. A two dimensionality of time-dependent motion would invalidate the above equation as well. However, in a recent study by Huang and $\mathrm{Li}$ (2017), for atmospheric cold front-induced circulations in Lake Pontchartrain, the above balance is shown to be quite robust with an $R^{2}$ value of greater than 0.90 . Li et al. (2018b) demonstrated that the quasi-steady state is achieved because a change in the wind vector would produce a seiche that dissipates quickly in $2-3$ cycles in a time period much shorter than a tidal cycle, allowing a quick adjustment to wind-driven flows in such systems with a limited connection with the coastal ocean through multiple narrow inlets.

The quasi-steady-state balance of Eq. (4) is checked with the model results and low-pass filtered wind data (Fig. 15). For the calculations, we selected a transect in the FVCOM model in the north-south direction and east-west direction, respectively, all along the center of the bay. The selected wind fetch from north to south is $21.5 \mathrm{~km}$ and that from east to west is about $8 \mathrm{~km}$. The water-depth values used in Eq. (4) are the average of the water depths at all the nodes of the model along 
the wind directions, which are 3.8 and $1.3 \mathrm{~m}$ along the north-south and east-west lines, respectively. The waterlevel difference calculated by the FVCOM model (solid black lines in Fig. 15) is obtained by subtraction of lowpass filtered water-level values. The results demonstrate again that the quasi-steady-state balance is a quite good approximation for the force balance with $R^{2}$ values of 0.78 and 0.88 for the momentum in east-west and northsouth directions, respectively. This means that on time scales comparable to or longer than the tidal time scales, the surface slope is approximately under a quasi-steadystate equilibrium between the wind stress and surface slope-produced pressure gradient, regardless if the wind changes with time or not. The water-level changes inside the bay are thus a result of direct wind forcing, and Ekman transport or Coriolis effect must be negligible in this context ( $\mathrm{Li}$ et al. 2018b). The wind-driven slopes inside the bay then drive the flow field in the inlets. The quasi-steady-state characteristics allow the use of low-pass filtered results (Figs. 9-12) at any time from the numerical experiment as if it is from a constant wind.

\section{b. Regression between atmospheric forcing and low-pass filtered flow}

The results have shown that wind is responsible for the subtidal exchange flows and transport modes discussed above (Fig. 14). This suggests that a regression model linking wind and subtidal flows may be established for empirical predictions. Because the wind stress is usually described by the quadratic law, wind velocity components should have squared terms in the regression. A regression based on this consideration and the dynamics (see appendix) is thus derived as

$$
\begin{aligned}
u(t)= & A W_{x}(t)+B W_{x}^{2}(t)+C W_{y}(t)+D W_{y}^{2}(t) \\
& +E\left(p_{a}-p_{a 0}\right)+F,
\end{aligned}
$$

in which $u(t), W_{x}(t), W_{y}(t), p_{a}$, and $p_{a 0}$ are, respectively, the time series of the low-pass filtered along-channel velocity component (positive inward), the east wind velocity component, the north wind velocity component, the air pressure, and the mean air pressure (averaged over time); $t$ is time; and $A, B, C, D, E$, and $F$ are the regression coefficients. In the calculations, all variables are 40-h low-pass filtered. The regression is done for all data from the two time periods for each station (Table 6). The $R^{2}$ values range from 0.464 to 0.571 .

The regression shows that the most important term is the north wind [with the coefficient $C$ in Eq. (5)]. For stations $\mathrm{CF}, \mathrm{CB}, \mathrm{CM}, \mathrm{BP}$, and $\mathrm{PA}$, the $C$ values are 0.86 , $0.63,1.62,0.59$, and 0.82 , respectively. The mean value $F$ is negative for all stations: for stations $\mathrm{CF}, \mathrm{CB}, \mathrm{CM}, \mathrm{BP}$, and PA, the $F$ values are $-9.93,-10.31,-5.36,-5.56$, and -4.59 , respectively. All the coefficients remain the same sign except for $B ; B$ reflects the effect of the east wind, which shows the least correlation with the flow as discussed earlier (Tables 2 and 3), and thus, it is not unexpected that it may change sign for $B$. This is because the east wind component can change sign regardless of whether it is during the pre- or postfrontal phase.

The comparison between the regression model results and data (Fig. 16) shows the similarity and discrepancy: the overall trend and variations are all consistent between the two, indicating that the model captures weather-induced fluctuations in the low-pass filtered along-channel flow. Note that the regressions, though having discrepancies with the data, can be used as a tool to predict or hindcast subtidal flows through these tidal passes, if the weather forcing is provided. At the present, there is no real-time observation system established at these inlets. The regression can thus be useful for a quick first-order estimate (or forecast) of the flows under the influence of the cold front weather systems. This also can be done retrospectively for estimations of flows and flow-related processes.

\section{c. Cold front strength index and regression with low-pass filtered flow}

The above regressions are made for the entire time series. They do not separate the normal weather from the cold front weather. To examine more closely how the cold front weather affects the low-pass filtered flow, we define a cold front strength index (CI):

$$
\mathrm{CI}=\frac{\Delta W\left(\mathrm{~m} \mathrm{~s}^{-1}\right)}{4\left(\mathrm{~m} \mathrm{~s}^{-1}\right)}+\frac{\Delta p_{a}(\mathrm{mb})}{30(\mathrm{mb})}
$$

Here $\Delta W$ is the mean wind speed during each of the 51 cold front events subtracting the mean value over the entire record $\left(\mathrm{m} \mathrm{s}^{-1}\right) ; \Delta p_{a}$ is the air pressure increase $(\mathrm{mb} ; 1 \mathrm{mb}=1 \mathrm{hPa})$ between the minimum pressure and the following maximum pressure. This cold front strength index is defined such that both the wind speed anomaly and air pressure change during a cold front passage are considered. The addition of these two factors is done after each of them is normalized by a selected "standard" value during a typical cold front: for the wind speed anomaly, it is $4 \mathrm{~m} \mathrm{~s}^{-1}$; while for the air pressure change, it is $30 \mathrm{mb}$. These are selected based on the variability of data. Usually, the wind speed variability during a cold front will be on the order of 4-5 $\mathrm{m} \mathrm{s}^{-1}$ and the air pressure variation within $30 \mathrm{mb}$ (Figs. 5b,d). With the normalization, we obtain a nondimensional value for CI. Next, we find the change in low-pass filtered along-channel velocity $\Delta u$ (range of 
TABLE 6. Regression coefficients using $u=A W_{x}+B W_{x}^{2}+C W_{y}+D W_{y}^{2}+E(p-\bar{p})+F$.

\begin{tabular}{|c|c|c|c|c|c|c|}
\hline \multirow{2}{*}{$\frac{\text { Station }}{\mathrm{CF}}$} & \multirow{2}{*}{$\frac{\text { Parameter }}{A}$} & \multirow{2}{*}{$\begin{array}{r}\text { Estimate } \\
0.095\end{array}$} & \multicolumn{2}{|c|}{$\begin{array}{c}95 \% \text { confidence } \\
\text { interval }\end{array}$} & \multirow{2}{*}{$\frac{R^{2}}{0.571}$} & \multirow[t]{2}{*}{ Comment } \\
\hline & & & 0.073 & 0.117 & & \\
\hline & B & 0.003 & -0.001 & 0.007 & & \\
\hline & $C$ & 0.859 & 0.834 & 0.884 & & \\
\hline & $D$ & -0.067 & -0.071 & -0.063 & & \\
\hline & $E$ & 0.250 & 0.241 & 0.259 & & \\
\hline & $F$ & -9.930 & -10.300 & -9.560 & & \\
\hline \multirow[t]{6}{*}{$\mathrm{CB}$} & $A$ & 0.069 & 0.055 & 0.083 & 0.482 & All data 2013-15 \\
\hline & $B$ & 0.014 & 0.011 & 0.017 & & \\
\hline & $C$ & 0.630 & 0.61 & 0.650 & & \\
\hline & $D$ & -0.055 & -0.062 & -0.048 & & \\
\hline & $E$ & 0.319 & 0.300 & 0.338 & & \\
\hline & $F$ & -10.310 & -11.345 & -9.275 & & \\
\hline \multirow[t]{6}{*}{$\mathrm{BP}$} & $A$ & -0.631 & -0.652 & -0.610 & 0.464 & All data 2013-15 \\
\hline & $B$ & -0.025 & -0.037 & -0.013 & & \\
\hline & $C$ & 0.590 & 0.575 & 0.605 & & \\
\hline & $D$ & -0.021 & -0.022 & -0.020 & & \\
\hline & $E$ & 0.223 & 0.207 & 0.239 & & \\
\hline & $F$ & -5.558 & -5.693 & -5.423 & & \\
\hline \multirow[t]{6}{*}{$\mathrm{PA}$} & $A$ & -0.854 & -0.879 & -0.8290 & 0.567 & Only $2013 / 14$ data (no valid data for $2014 / 15$ ) \\
\hline & $B$ & 0.021 & 0.016 & 0.0260 & & \\
\hline & $C$ & 0.819 & 0.802 & 0.8360 & & \\
\hline & $D$ & -0.005 & -0.007 & -0.0030 & & \\
\hline & $E$ & 0.238 & 0.219 & 0.2570 & & \\
\hline & $F$ & -4.591 & -4.717 & -4.4650 & & \\
\hline \multirow[t]{6}{*}{$\mathrm{CM}$} & $A$ & 0.886 & 0.855 & 0.917 & 0.584 & Only $2014 / 15$ data (no data for $2013 / 14$ ) \\
\hline & $B$ & 0.049 & 0.044 & 0.054 & & \\
\hline & $C$ & 1.623 & 1.599 & 1.647 & & \\
\hline & $D$ & -0.045 & -0.048 & -0.042 & & \\
\hline & $E$ & 0.409 & 0.385 & 0.433 & & \\
\hline & $F$ & -5.364 & -5.555 & -5.173 & & \\
\hline
\end{tabular}

variation) and do another linear regression between $\Delta u$ and CI. We use a dimensional $\Delta u$ on purpose as it is more intuitive to relate the cold front intensity with flow in a common velocity unit (here we use centimeters per second). The results of a direct regression between these two quantities show (Fig. 17) the trend of increasing CI leading to an increased $\Delta u$. This is true for all stations. The $R^{2}$ values for this regression for $\mathrm{BP}, \mathrm{CF}, \mathrm{PA}$, and $\mathrm{CB}$ stations are $0.3531,0.8286,0.7033$, and 0.8754 , respectively. Except the BP station, all the stations show fairly good correlations between the forcing factors and response. This further verifies from another viewpoint that the low-pass filtered along-channel velocity is strongly correlated with cold fronts.

\section{Summary}

Circulations and transport in the Barataria Bay area under 51 cold fronts are studied in this work. As background information, tidal currents in the tidal passes of Barataria Bay are first determined to be dominated by the $\mathrm{K}_{1}, \mathrm{O}_{1}$, and $\mathrm{P}_{1}$ constituents. The semidiurnal tidal constituents of the flows are less than $1 / 4$ of the diurnal constituents. Excluding the noise (beyond the $\mathrm{M}_{8}$ frequency), about $22 \%-29 \%$ of the velocity amplitude can be attributed to tidal motions. The subtidal components contribute about the same percentage to the velocity amplitude $(23 \%-30 \%)$.

The overtidal components have a larger percentage $(\sim 33 \%-43 \%)$. This is partly because of the broad and noisy band and partly because of the nonlinear contribution of the higher harmonics. The intertidal components of the flow are relatively small in magnitude $(\sim 8 \%-12 \%)$. All these high-frequency components in the spectrum however do not contribute to the low-pass filtered flows or long-term transport.

During the study period, the north component of the wind vector is found to be the major contributor to the subtidal flow through the inlets. The weather band coherence is much higher, indicating strong influence of cold fronts. The regression model reasonably captures the effect of weather on the subtidal flows and provides a tool for prediction of subtidal flows through tidal passes given the weather data. By defining a normalized cold 

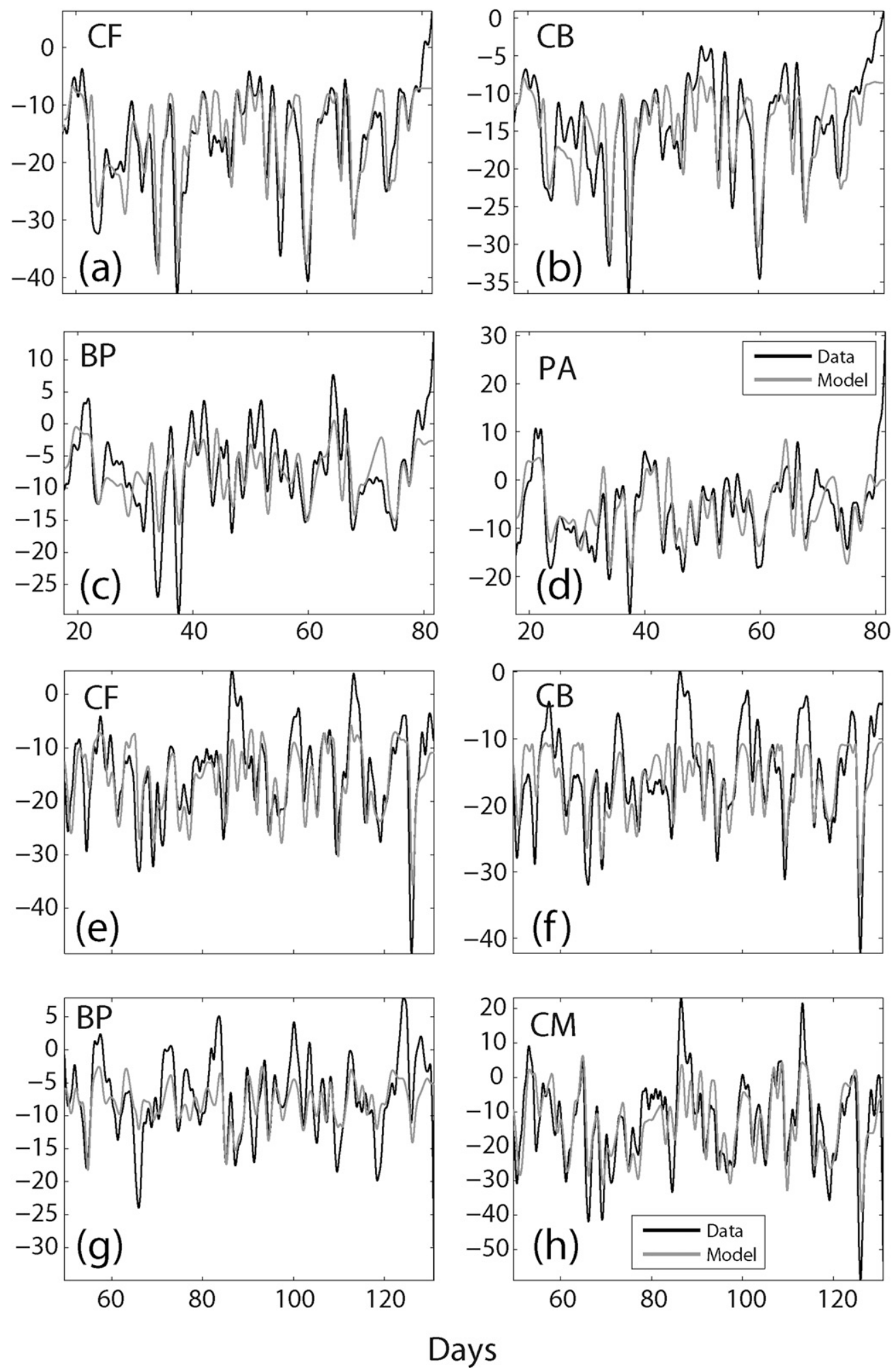

FIG. 16. Comparison between regression model results and data at stations (a) CF, (b) CB, (c) BP, and (d) PA and at stations (e) CF, (f) CB, (g) BP, and (h) CM for the entire time period (2013/14 and 2014/15). 


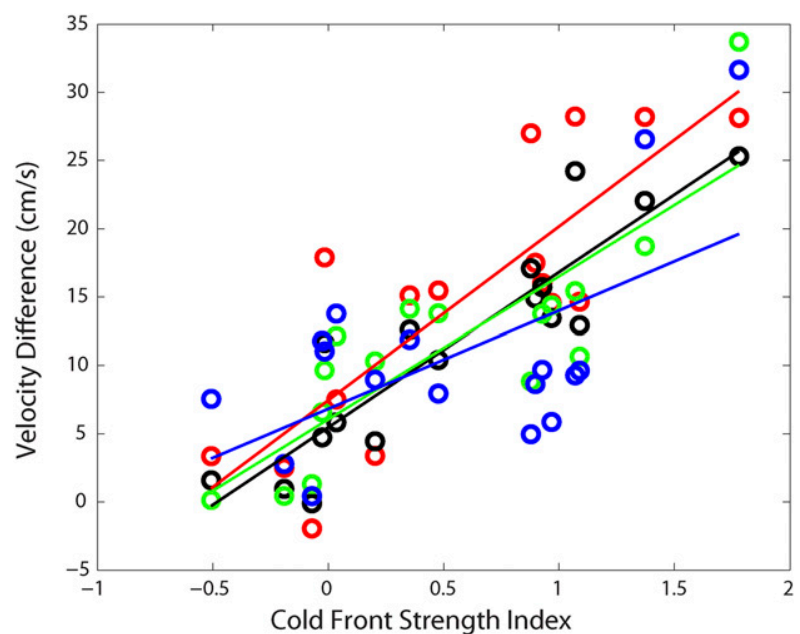

FIG. 17. Regression between the cold front strength index and the change in low-pass filtered flow during the cold front events. The blue, red, green, and black circles represent data for the BP, $\mathrm{CF}, \mathrm{PA}$, and $\mathrm{CB}$ stations, respectively.

front strength index $(\mathrm{CI})$, another regression with the along-channel flow is done, showing the relations between forcing (during cold fronts only) and response, verifying that the subtidal flows in the multiple inlets are induced by the repeated cold fronts.

The quasi-steady state provides a good approximation in calculating the surface slopes driven by the cold fronts. The $R^{2}$ value is large (0.78 and 0.88 ) for results in the east-west and north-south directions, respectively, comparable to those in Lake Pontchartrain (Huang and Li 2017) and those in the Elson Lagoon of the northern Alaska (Li et al. 2019).

Along the shallow shoals inside the bay, flows tend to be in the downwind direction; while in relatively deep channels, flows tend to be upwind, consistent with, for example, Lin et al. (2016). Flows through the multiple inlets are consistent with previous theory and observations ( $\mathrm{Li} 2013$; Duran-Matute et al. 2016) such that the upwind inlets tend to have inward flows and the downwind inlets outward flows; the shallow inlets tend to have downwind flows and deeper inlets tend to have counterwind flows.

The forcing-response joint EOF analysis suggests three major cold front-related wind-driven transport modes of the system. The first mode (45\%) describes an all-in or all-out transport through all the four inlets when the wind vector is perpendicular to the coastline or parallel to the main axis of the bay. The second mode $(41 \%)$ corresponds to mainly the wind-relaxation periods when the central deeper (Barataria Pass) or broader (Pass Abel) inlets tend to develop upwind flows while the other inlets leading to shallow shoals maintain a downwind direction flows when the wind is south-southwesterly or north-northeasterly. The third mode $(13 \%)$ is under wind that is almost due south or due north when the transport develops a tendency to have an inward flux in the upwind inlets but outward flux in the downwind inlets, consistent with Li (2013).

The tidal transport is persistent in relative ratios but mostly through Barataria Pass (57\%) and Pass Abel $(21 \%)$. Only $12 \%$ and $9 \%$ are through the Quatre Bayou and Caminada, respectively. The subtidal transport however varies substantially due to the cold front winds but on average about 1/3 through Barataria Pass and 1/3 through Pass Abel. The remaining transport is roughly split halfhalf between Caminada Pass and Quatre Bayou Pass.

Acknowledgments. This study was supported by the Louisiana Coastal Protection and Restoration Authority (CPRA) through the CPRA Interagency Agreement 2514-1401; and NOAA NA09NOS4780230 and through GCOOS with NOAA-NOS-IOOS-2016-2004378. Study collaboration and funding were also provided by the U.S. Department of the Interior, Bureau of Ocean Energy Management, Coastal Marine Institute, Washington, D.C., under Agreement Number M15AC00015. The work was conducted by the research team at Wave-CurrentSurge Information System (WAVCIS; http://www.wavcis. lsu.edu/). We thank Changsheng Chen and his FVCOM team at the University of Massachusetts for their generous assistance on using FVCOM. Comments from anonymous reviewers that helped the improvement of the manuscript are appreciated. Our computation using the FVCOM was performed on the cluster computer of the Louisiana Optical Network Initiative (LONI) HPC systems at LSU. The study was also supported by the NSF (OCE0554674, DEB-0833225, OCE-1140307, EAR-1139997). Data used in this study are available online (from wavcis.lsu.edu) after acceptance of the article.

\section{APPENDIX}

\section{The Dynamics Support of the Regression Model}

We use the linearized shallow-water equations, with both bottom friction and wind stress included, that is,

$$
\begin{aligned}
& \frac{\partial u}{\partial t}-f v=-g \frac{\partial \zeta}{\partial x}+\frac{\tau_{a x}}{\rho h}-\frac{\tau_{b x}}{\rho h}-\frac{1}{\rho} \frac{\partial p_{a}}{\partial x}, \\
& \frac{\partial v}{\partial t}+f u=-g \frac{\partial \zeta}{\partial y}+\frac{\tau_{a y}}{\rho h}-\frac{\tau_{b y}}{\rho h}-\frac{1}{\rho} \frac{\partial p_{a}}{\partial y}, \text { and } \\
& \frac{\partial \zeta}{\partial t}+\frac{\partial h u}{\partial x}+\frac{\partial h v}{\partial y}=0 .
\end{aligned}
$$

By filtering out the tidal oscillation (low-pass filtering), a quasi-steady state (Huang and Li 2017) can be reached 
to have the subtidal flow fields to satisfy the following equations:

$$
\begin{aligned}
& -f \bar{v}=-g \frac{\partial \bar{\zeta}}{\partial x}+\frac{\bar{\tau}_{a x}}{\rho h}-\frac{\bar{\tau}_{b x}}{\rho h}-\frac{1}{\rho} \frac{\partial \bar{p}_{a}}{\partial x}, \\
& f \bar{u}=-g \frac{\partial \bar{\zeta}}{\partial y}+\frac{\bar{\tau}_{a y}}{\rho h}-\frac{\bar{\tau}_{b y}}{\rho h}-\frac{1}{\rho} \frac{\partial \bar{p}_{a}}{\partial y}, \quad \text { and } \\
& \frac{\partial h \bar{u}}{\partial x}+\frac{\partial h \bar{v}}{\partial y}=0,
\end{aligned}
$$

in which the meanings of the variables remain the same, except that all of them are the subtidal version of their counterparts, respectively. For that reason, they all have a bar over the name of each variable.

The temporally averaged (subtidal) wind stress is

$$
\boldsymbol{\tau}_{a}=\rho C_{D a} \mathbf{w}|\mathbf{w}|,
$$

in which $\tau_{a}$ is the wind stress vector, $C_{D a}$ is the wind drag coefficient on the ocean surface, and $\mathbf{w}$ is the wind velocity vector. The bottom stress has a similar equation as Eq. (A7) relating the bottom stress and horizontal velocity.

Equations (A4), (A5), and (A6) have three unknowns: $(\bar{u}, \bar{v}, \bar{\zeta})$. With a proper boundary condition, a solution can be obtained for the unknowns. However, with the complicated bathymetry, coastlines, and temporally and spatially varying forcing factors, it is impossible to obtain an exact and general (or even a special) solution. Here we will only provide some dynamic support for the use of the regression model [Eq. (5) in the main text]. We will establish a rationale of why Eq. (5) is used to examine the statistical relationships among the flow field and atmospheric forcing (wind speed and atmospheric pressure).

Any solution for $(\bar{u}, \bar{v}, \bar{\zeta})$ can be expressed in theory by the general format:

$$
\left(\begin{array}{l}
\bar{u} \\
\bar{v} \\
\bar{\zeta}
\end{array}\right)=\left[\begin{array}{l}
\bar{u}\left(\Delta p_{a}, \tau_{x}, \tau_{y}\right) \\
\bar{v}\left(\Delta p_{a}, \tau_{x}, \tau_{y}\right) \\
\bar{\zeta}\left(\Delta p_{a}, \tau_{x}, \tau_{y}\right)
\end{array}\right],
$$

in which the air pressure anomaly $\Delta p_{a}=p_{a}-p_{a 0}$ and $p_{a 0}$ is the background, or environmental air pressure or the average air pressure at sea level. One might be tempted to consider that the air pressure gradient could be very small. However, in a cold front situation, this is not guaranteed as the change in air pressure can have a scale of $\sim 30 \mathrm{mb}$. It is rather safe to retain the terms including the air pressure than drop them out. At the very least, if the air pressure change is not important, the resultant regression (see below) would provide small coefficients. Note that the Coriolis force is included for completeness. If the Coriolis effect is negligible, the above solution format remains the same. Now let us do a Taylor series expansion for the above equation in terms of the variables $\Delta p_{a}, \tau_{x}$, and $\tau_{y}$ to the first order:

$$
\left(\begin{array}{c}
\bar{u} \\
\bar{v} \\
\bar{\zeta}
\end{array}\right)=\left[\begin{array}{c}
\bar{u}(0,0,0)+\frac{\partial \bar{u}}{\partial p_{a}} \Delta p_{a}+\frac{\partial \bar{u}}{\partial \tau_{x}} \tau_{x}+\frac{\partial \bar{u}}{\partial \tau_{y}} \tau_{y} \\
\bar{v}(0,0,0)+\frac{\partial \bar{v}}{\partial \tau_{x}} \tau_{x}+\frac{\partial \bar{v}}{\partial \tau_{y}} \tau_{y} \\
\bar{\zeta}(0,0,0)+\frac{\partial \bar{\zeta}}{\partial \tau_{x}} \tau_{x}+\frac{\partial \bar{\zeta}}{\partial \tau_{y}} \tau_{y}
\end{array}\right]
$$

All the derivatives in Eq. (A9) are evaluated at $(0,0,0)$ for $\left(\Delta p_{a}, \tau_{x}, \tau_{y}\right)$. Note that, for the quadratic wind stress, similar to the quadratic bottom friction, another Taylor series expansion (e.g., Proudman 1953; Parker 1984) can be used to express the quadratic velocity law for the stress in terms of a linear term and another term proportional to velocity squared; that is,

$$
\begin{gathered}
\tau_{x}=\alpha w_{x}+\beta w_{x}^{2}+\text { higher-order terms } \\
\tau_{y}=\gamma w_{y}+\delta w_{y}^{2}+\text { higher-order terms }
\end{gathered}
$$

where $\alpha, \beta, \gamma$, and $\delta$ are all constants of the Taylor series expansions. Substituting Eqs. (A10) and (A11) into Eq. (A9) and neglecting the higher-order terms, we obtain

$$
\left(\begin{array}{c}
\bar{u} \\
\bar{v} \\
\bar{\zeta}
\end{array}\right)=\left[\begin{array}{c}
\bar{u}(0,0,0)+\frac{\partial \bar{u}}{\partial p_{a}} \Delta p_{a}+\frac{\partial \bar{u}}{\partial \tau_{x}}\left(\alpha w_{x}+\beta w_{x}^{2}\right)+\frac{\partial \bar{u}}{\partial \tau_{y}}\left(\gamma w_{y}+\delta w_{y}^{2}\right) \\
\bar{v}(0,0,0)+\frac{\partial \bar{v}}{\partial \tau_{x}}\left(\alpha w_{x}+\beta w_{x}^{2}\right)+\frac{\partial \bar{v}}{\partial \tau_{y}}\left(\gamma w_{y}+\delta w_{y}^{2}\right) \\
\bar{\zeta}(0,0,0)+\frac{\partial \bar{\zeta}}{\partial \tau_{x}}\left(\alpha w_{x}+\beta w_{x}^{2}\right)+\frac{\partial \bar{\zeta}}{\partial \tau_{y}}\left(\gamma w_{y}+\delta w_{y}^{2}\right)
\end{array}\right]
$$


This can be rewritten as

$$
\left(\begin{array}{c}
\bar{u} \\
\bar{v} \\
\bar{\zeta}
\end{array}\right)=\left(\begin{array}{c}
A w_{x}+B w_{x}^{2}+C w_{y}+D w_{y}^{2}+E \Delta p_{a}+F \\
G w_{x}+H w_{x}^{2}+I w_{y}+J w_{y}^{2}+K \Delta p_{a}+L \\
M w_{x}+N w_{x}^{2}+O w_{y}+P w_{y}^{2}+Q \Delta p_{a}+R
\end{array}\right),
$$

in which, $A=\alpha \partial \bar{u} / \partial \tau_{x}, B=\beta \partial \bar{u} / \partial \tau_{x}, C=\gamma \partial \bar{u} / \partial \tau_{y}, D=$ $\delta \partial \bar{u} / \partial \tau_{y}, E=\partial \bar{u} / \partial p_{a}, F=\bar{u}(0,0,0), G=\alpha \partial \bar{v} / \partial \tau_{x}, H=$ $\beta \partial \bar{v} / \partial \tau_{x}, I=\gamma \partial \bar{v} / \partial \tau_{y}, J=\delta \partial \bar{v} / \partial \tau_{y}, K=\partial \bar{v} / \partial p_{a}, L=\bar{v}(0$, $0,0), M=\alpha \partial \bar{\zeta} / \partial \tau_{x}, N=\beta \partial \bar{\zeta} / \partial \tau_{x}, O=\gamma \partial \bar{\zeta} / \partial \tau_{y}, P=\delta \partial \bar{\zeta} /$ $\partial \tau_{y}, Q=\partial \bar{\zeta} / \partial p_{a}$, and $R=\bar{\zeta}(0,0,0)$. The first equation in Eq. (A13) is Eq. (5) in the main text. It should be noted that this appendix provides the rationale of the use of Eq. (5). It is not an explicit solution as the coefficients are all unknowns. However, this provides the dynamics bases for the statistical regression, though not all statistical regressions have such bases.

\section{REFERENCES}

Allahdadi, M. N., and C. Li, 2017: Numerical simulation of Louisiana shelf circulation under Hurricane Katrina. J. Coastal Res., 34, 67-80, https://doi.org/10.2112/JCOASTRES-D-16-00129.1.

Barras, J., and Coauthors, 2003: Historical and projected coastal Louisiana land changes: 1978-2050. USGS Rep. OFR 03-334, 45 pp., https://doi.org/10.3133/ofr03334.

Boon, J., 2004: Secrets of the Tide: Tide and Tidal Current Analysis and Predictions, Storm Surges and Sea Level Trends. Horwood Publishing, $210 \mathrm{pp}$.

Britsch, L. D., and J. B. Dunbar, 1993: Land loss rates: Louisiana coastal plain. J. Coastal Res., 9, 324-338.

Bruno, D. O., and E. M. Acha, 2015: Winds vs. tides: Factors ruling the recruitment of larval and juvenile fishes into a micro-tidal and shallow choked lagoon (Argentina). Environ. Biol. Fishes, 98, 1449-1458, https://doi.org/10.1007/s10641-014-0371-3.

Butterworth, S., 1930: On the theory of filter amplifiers. Exp. Wireless Wireless Eng., 7, 536-541.

Cahoon, D. R., D. J. Reed, J. W. Day Jr., G. D. Steyer, R. M. Boumans, J. C. Lynch, D. McNally, and N. Latif, 1995: The influence of Hurricane Andrew on sediment distribution in Louisiana coastal marshes. J. Coastal Res., 21, 280-294.

Chaney, P. L., and G. W. Stone, 1996: Soundside shoreline erosion and implications for winter cold front forcing: West Ship Island, Mississippi. Shore Beach, 64, 27-33.

Chen, C., H. Liu, and R. C. Beardsley, 2003: An unstructured grid, finite-volume, three-dimensional, primitive equation ocean model: Application to coastal ocean and estuaries. J. Atmos. Oceanic Technol., 20, 159-186, https://doi.org/10.1175/15200426(2003)020<0159:AUGFVT>2.0.CO;2.

Conner, W. H., J. W. Day Jr., R. H. Baumann, and J. M. Randall, 1989: Influence of hurricanes on coastal ecosystems along the northern Gulf of Mexico. Wetlands Ecol. Manage., 1, 45-56, https://doi.org/10.1007/BF00177889.

Couvillion, B. R., and Coauthors, 2011: Land area change in coastal Louisiana from 1932 to 2010. USGS Map 3164, 19 pp.

Das, A., D. Justic, E. Swenson, R. E. Turner, M. Inoue, and D. Park, 2011: Coastal land loss and hypoxia: The "outwelling" hypothesis revisited. Environ. Res. Lett., 6, 025001, https:// doi.org/10.1088/1748-9326/6/2/025001.

- - - M. Inoue, A. Hoda, H. Huang, and D. Park, 2012: Impacts of Mississippi River diversions on salinity gradients in a deltaic Louisiana estuary: Ecological and management implications. Estuarine Coastal Shelf Sci., 111, 17-26, https:// doi.org/10.1016/j.ecss.2012.06.005.

Day, J. W., Jr., and Coauthors, 2007: Restoration of the Mississippi delta: Lessons from Hurricanes Katrina and Rita. Science, $\mathbf{3 1 5}$, 1679-1684, https://doi.org/10.1126/science.1137030.

de Miranda, L. B., F. P. Andutta, B. Kjerfve, and B. M. de Castro Filho, 2017: Fundamentals of Estuarine Physical Oceanography. Springer, 480 pp.

Dingler, J. R., T. E. Reiss, and N. G. Plant, 1993: Erosional patterns of the Isles Dernieres, Louisiana, in relation to meteorological influences. J. Coastal Res., 9, 112-125.

Dronkers, J. J., 1964: Tidal Computation in Rivers and Coastal Waters. North-Holland, 518 pp.

Duran-Matute, M., T. Gerkema, and M. G. Sassi, 2016: Quantifying the residual volume transport through a multiple-inlet system in response to wind forcing: The case of the western Dutch Wadden Sea. J. Geophys. Res. Oceans, 121, 8888-8903, https://doi.org/10.1002/2016JC011807.

Dyer, K. R., 1997: Estuaries: A Physical Introduction. John Wiley and Sons, $195 \mathrm{pp}$.

Ebersole, B. A., J. J. Westerink, S. Bunya, J. C. Dietrich, and M. A. Cialone, 2010: Development of storm surge which led to flooding in St. Bernard polder during Hurricane Katrina. Ocean Eng., 37, 91-103, https://doi.org/10.1016/j.oceaneng.2009.08.013.

Emery, W. J., and R. E. Thomson, 2004: Data Analysis Methods in Physical Oceanography. 2nd ed. Elsevier, 654 pp.

Fearnley, S. M., M. D. Miner, M. Kulp, C. Bohling, and S. Penland, 2009: Hurricane impact and recovery shoreline change analysis of the Chandeleur Islands, Louisiana, USA: 1855 to 2005. Geo-Mar. Lett., 29, 455-466, https://doi.org/10.1007/s00367009-0155-5.

Feng, Z., and C. Li, 2010: Cold-front-induced flushing of the Louisiana Bays. J. Mar. Syst., 82, 252-264, https://doi.org/10.1016/ j.jmarsys.2010.05.015.

FitzGerald, D. M., M. S. Fenster, B. A. Argow, and I. V. Buynevich, 2008: Coastal impacts due to sea-level rise. Annu. Rev. Earth Planet. Sci., 36, 601-647, https://doi.org/10.1146/ annurev.earth.35.031306.140139.

Forbes, M. J., 1988: Hydrologic investigations of the lower Calcasieu River, Louisiana. USGS Rep. 87-4173, 61 pp.

Fritz, H. M., and Coauthors, 2007: Hurricane Katrina storm surge distribution and field observations on the Mississippi Barrier Islands. Estuarine Coastal Shelf Sci., 74, 12-20, https://doi.org/ 10.1016/j.ecss.2007.03.015.

Gallo, M. N., and S. B. Vinzon, 2005: Generation of overtides and compound tides in Amazon estuary. Ocean Dyn., 55, 441-448, https://doi.org/10.1007/s10236-005-0003-8.

Guntenspergen, G. R., D. R. Cahoon, J. Grace, G. D. Fournet, M. A. Townson, and A. L. Foote, 1995: Disturbance and recovery of the Louisiana coastal marsh landscape from the impacts of Hurricane Andrew. J. Coastal Res., 11 (21), 324-339.

Harris, D. L., 1981: Tides and tidal datums in the United States U.S. Army Corps of Engineers Special Rep. 7, 382 pp.

Herrling, G., and C. Winter, 2015: Tidally- and wind-driven residual circulation at the multiple-inlet system East Frisian Wadden Sea. Cont. Shelf Res., 106, 45-59, https://doi.org/ 10.1016/j.csr.2015.06.001. 
Hill, D. F., S. D. Griffiths, W. R. Peltier, B. P. Horton, and T. E. Törnqvist, 2011: High-resolution numerical modeling of tides in the western Atlantic, Gulf of Mexico, and Caribbean Sea during the Holocene. J. Geophys. Res., 116, C10014, https:// doi.org/10.1029/2010JC006896.

Houston, S. H., W. A. Shaffer, M. D. Powell, and J. Chen, 1999: Comparisons of HRD and SLOSH surface wind fields in hurricanes: Implications for storm surge modeling. Wea. Forecasting, 14, 671-686, https://doi.org/10.1175/1520-0434(1999) $014<0671$ :COHASS $>2.0$.CO 2 .

Huang, W., and C. Li, 2017: Cold front driven flows through multiple inlets of Lake Pontchartrain estuary. J. Geophys. Res. Oceans, 122, 8627-8645, https://doi.org/10.1002/2017JC012977.

— , H. Sun, S. Nnaji, and W. K. Jones, 2002: Tidal hydrodynamics in a multiple-inlet estuary: Apalachicola Bay, Florida. J. Coastal Res., 18, 674-684.

Hubbert, G. D., and K. L. McInnes, 1999: A storm surge model for coastal planning and impact studies. J. Coastal Res., 15, 168-185.

Ianniello, J. P., 1977: Tidally induced residual currents in estuaries of constant breadth and depth. J. Mar. Res., 35, 755-785.

_ 1979: Tidally induced residual currents in estuaries of variable breadth and depth. J. Phys. Oceanogr., 9, 962-974, https:// doi.org/10.1175/1520-0485(1979)009<0962:TIRCIE >2.0.CO;2.

Inoue, M., D. Park, D. Justic, and W. J. Wiseman Jr., 2008: A highresolution integrated hydrology-hydrodynamic model of the Barataria Basin system. Environ. Modell. Software, 23, 1122 1132, https://doi.org/10.1016/j.envsoft.2008.02.011.

Kantha, L., 2005: Barotropic tides in the Gulf of Mexico. Circulation in the Gulf of Mexico: Observations and Models, Geophys. Monogr., Vol. 161, Amer. Geophys. Union, 159-163.

Keen, T. R., 2002: Waves and currents during a winter cold front in the Mississippi Bight, Gulf of Mexico: Implications for barrier island erosion. J. Coastal Res., 18, 622-636.

Kent, J. D., and R. K. Dokka, 2013: Potential impacts of long-term subsidence on the wetlands and evacuation routes in coastal Louisiana. GeoJournal, 78, 641-655, https://doi.org/10.1007/ s10708-012-9457-7.

Khalil, S. M., and D. M. Lee, 2006: Restoration of Isles Dernieres, Louisiana: Some reflections on morphodynamic approaches in the northern Gulf of Mexico to conserve coastal/marine systems. J. Coastal Res., 22 (39), 65-71.

Li, C., 2013: Subtidal water flux through a multiple-inlet system: Observations before and during a cold front event and numerical experiments. J. Geophys. Res. Oceans, 118, 1877-1892, https://doi.org/10.1002/jgrc.20149.

_ - and J. O'Donnell, 2005: The effect of channel length on the residual circulation in tidally dominated channels. J. Phys. Oceanogr., 35, 1826-1840, https://doi.org/10.1175/JPO2804.1.

_- J. R. White, C. Chen, H. Lin, E. Weeks, K. Galvan, and S. Bargu, 2011: Summertime tidal flushing of Barataria Bay: Transports of water and suspended sediments. J. Geophys. Res., 116, C04009, https://doi.org/10.1029/ 2010JC006566.

— E. Weeks, B. Milan, W. Huang, and R. Wu, 2018a: Weatherinduced transport through a tidal channel calibrated by an unmanned boat. J. Atmos. Oceanic Technol., 35, 261-279, https://doi.org/10.1175/JTECH-D-17-0130.1.

_ W. Wuang, C. Chen, and H. Lin, 2018b: Flow regimes and adjustment to wind-driven motions of Lake Pontchartrain estuary: A modeling experiment using FVCOM. J. Geophys. Res. Oceans, 123, 8460-8488, https://doi.org/10.1029/2018JC013985.

_- K. M. Boswell, N. Chaichitehrani, W. Huang, and R. Wu, 2019: Weather induced subtidal flows through multiple inlets of an Arctic microtidal lagoon. Acta Oceanol. Sin., 38, 1-16, https://doi.org/10.1007/s13131-019-1361-2.

Lin, J., C. Li, K. M. Boswell, M. Kimball, and L. Rozas, 2016: Examination of winter circulation in a northern Gulf of Mexico estuary. Estuaries Coasts, 39, 879-899, https://doi.org/ 10.1007/s12237-015-0048-y.

Marmer, H. A., 1948: Is the Atlantic coast sinking? The evidence from the tide. Geogr. Rev., 38, 652-657, https://doi.org/ $10.2307 / 211451$.

Moeller, C. C., O. K. Huh, H. H. Roberts, L. E. Gumley, and W. P. Menzel, 1993: Response of Louisiana coastal environments to cold front passage. J. Coastal Res., 9, 434-447.

Morton, R. A., 2008: Historical changes in the Mississippi-Alabama barrier-island chain and the roles of extreme storms, sea level, and human activities. J. Coastal Res., 24, 1587-1600, https://doi.org/10.2112/07-0953.1.

— , and A. H. Sallenger Jr., 2003: Morphological impacts of extreme storms on sandy beaches and barriers. J. Coastal Res., 19, 560-573.

_ , and J. A. Barras, 2011: Hurricane impacts on coastal wetlands: A half-century record of storm-generated features from southern Louisiana. J. Coastal Res., 27, 27-43, https://doi.org/ 10.2112/JCOASTRES-D-10-00185.1.

Mulrennan, M. E., and C. Woodroffe, 1998: Saltwater intrusion into the coastal plains of the lower Mary River, Northern Territory, Australia. J. Environ. Manage., 54, 169-188, https:// doi.org/10.1006/jema.1998.0229.

Neubauer, S. C., 2013: Ecosystem responses of a tidal freshwater marsh experiencing saltwater intrusion and altered hydrology. Estuaries Coasts, 36, 491-507, https://doi.org/10.1007/s12237011-9455-x.

Niedoroda, A. W., D. T. Resio, G. R. Toro, D. Divoky, H. S. Das, and C. W. Reed, 2010: Analysis of the coastal Mississippi storm surge hazard. Ocean Eng., 37, 82-90, https://doi.org/ 10.1016/j.oceaneng.2009.08.019.

Otvos, E. G., and G. A. Carter, 2008: Hurricane degradationbarrier development cycles, northeastern Gulf of Mexico: Landform evolution and island chain history. J. Coastal Res., 24, 463-478, https://doi.org/10.2112/06-0820.1.

Padman, L., and S. Erofeeva, 2004: A barotropic inverse tidal model for the Arctic Ocean. Geophys. Res. Lett., 31, L02303, https://doi.org/10.1029/2003GL019003.

Palaseanu-Lovejoy, M., C. Kranenburg, J. A. Barras, and J. C. Brock, 2013: Land loss due to recent hurricanes in coastal Louisiana, USA. J. Coastal Res., 29 (63), 97-109, https://doi.org/ 10.2112/SI63-009.1.

Parker, B. B., 1984: Frictional effects on the tidal dynamics of shallow estuary. Ph.D. dissertation, Johns Hopkins University, 291 pp.

Peng, M., L. Xie, and L. J. Pietrafesa, 2004: A numerical study of storm surge and inundation in the Croatan-AlbemarlePamlico estuary system. Estuarine Coastal Shelf Sci., 59, 121-137, https://doi.org/10.1016/j.ecss.2003.07.010.

,,- and,- 2006 : Tropical cyclone induced asymmetry of sea level surge and fall and its presentation in a storm surge model with parametric wind fields. Ocean Modell., 14, 81-101, https://doi.org/10.1016/j.ocemod.2006.03.004.

Penland, S., H. H. Roberts, S. J. Williams, A. H. Sallenger Jr., D. R. Cahoon, D. W. Davis, and C. G. Groat, 1990: Coastal land loss in Louisiana. Preprints, 40th Annual Meeting, Lafayette, LA, Gulf Coast Association of Geological Societies, 685-699.

, P. F. Connor Jr., A. Beall, S. Fearnley, and S. J. Williams, 2005: Changes in Louisiana's shoreline: 1855-2002. J. Coastal Res., 21 (44), 7-39. 
Pepper, D. A., and G. W. Stone, 2004: Hydrodynamic and sedimentary responses to two contrasting winter storms on the inner shelf of the northern Gulf of Mexico. Mar. Geol., 210, 43-62, https://doi.org/10.1016/j.margeo.2004.05.004.

Pezeshki, S. R., R. D. Delaune, and W. H. Patrick Jr., 1990: Flooding and saltwater intrusion: Potential effects on survival and productivity of wetland forests along the U.S. Gulf Coast. For. Ecol. Manage., 33-34, 287-301, https://doi.org/10.1016/ 0378-1127(90)90199-L.

Proudman, J., 1953: Dynamical Oceanography. Wiley, 409 pp.

Pugh, D. T., 1987: Tides, Surges and Mean Sea Level. John Wiley and Sons, $472 \mathrm{pp}$.

Rego, J. L., and C. Li, 2009: On the importance of the forward speed of hurricanes in storm surge forecasting: A numerical study. Geophys. Res. Lett., 36, L07609, https://doi.org/10.1029/ 2008 GL036953.

, and - 2010: Nonlinear terms in storm surge predictions: Effect of tide and shelf geometry with case study from Hurricane Rita. J. Geophys. Res., 115, C06020, https://doi.org/ 10.1029/2009JC005285.

Roberts, H. H., 1997: Dynamic changes of the Holocene Mississippi River delta plain: The delta cycle. J. Coastal Res., 13, 605-627.

, O. K. Huh, S. A. Hsu, L. J. Rouse Jr., and D. Rickman, 1989: Winter storm impacts on the Chenier Plain coast of southwestern Louisiana. Preprints, 39th Annual Meeting, Corpus Christi, TX, Gulf Coast Association of Geological Societies, 515-522.

- N. D. Walker, A. Sheremet, and G. W. Stone, 2005: Effects of cold fronts on bayhead delta development: Atchafalaya Bay, Louisiana, USA. High Resolution Morphodynamics and Sedimentary Evolution of Estuaries, Springer, 269-298.

- R. D. Delaune, J. R. White, C. Li, C. E. Sasser, D. Braud, E. Weeks, and S. Khalil, 2015: Floods and cold front passages: Impacts on coastal marshes in a river diversion setting (Wax Lake delta area, Louisiana). J. Coastal Res., 315, 1057-1068, https://doi.org/10.2112/JCOASTRES-D-14-00173.1.

Roberts, J., and T. D. Roberts, 1978: Use of the Butterworth lowpass filter for oceanographic data. J. Geophys. Res., 83, 55105514, https://doi.org/10.1029/JC083iC11p05510.

Salles, P., G. Voulgaris, and D. G. Aubrey, 2005: Contribution of nonlinear mechanisms in the persistence of multiple tidal inlet systems. Estuarine Coastal Shelf Sci., 65, 475-491, https://doi.org/10.1016/j.ecss.2005.06.018.

Sassi, M., M. Duran-Matute, T. van Kessel, and T. Gerkema, 2015: Variability of residual fluxes of suspended sediment in a multiple tidal-inlet system: The Dutch Wadden Sea. Ocean Dyn., 65, 1321-1333, https://doi.org/10.1007/s10236-015-0866-2.

Shuckburgh, E., D. Mitchell, and P. Stott, 2017: Hurricanes Harvey, Irma and Maria: How natural were these "natural disasters"? Weather, 72, 353-354, https://doi.org/10.1002/wea.3190.

Smith, J. M., M. A. Cialone, T. V. Wamsley, and T. O. McAlpin, 2010: Potential impact of sea level rise on coastal surges in southeast Louisiana. Ocean Eng., 37, 37-47, https://doi.org/ 10.1016/j.oceaneng.2009.07.008.

Stearns, S. D., and D. R. Hush, 2011: Digital Signal Processing with Examples in MATLAB. 2nd ed. CRC Press, 483 pp.

Steyer, G. D., B. C. Perez, S. Piazza, and G. Suir, 2007: Potential consequences of saltwater intrusion associated with hurricanes Katrina and Rita. Science and the storms: The USGS response to the hurricanes of 2005, USGS Rep. 1306, 137-145.

Stone, G. W., J. M. Grymes III, J. R. Dingler, and D. A. Pepper, 1997: Overview and significance of hurricanes on the Louisiana coast, U.S. J. Coastal Res., 13, 656-669.
- B. Liu, D. A. Pepper, and P. Wang, 2004: The importance of extratropical and tropical cyclones on the short-term evolution of barrier islands along the northern Gulf of Mexico, USA. Mar. Geol., 210, 63-78, https://doi.org/10.1016/j.margeo.2004.05.021.

Valle Levinson, A., C. Li, T. C. Royer, and L. P. Atkinson, 1998: Flow patterns at the Chesapeake Bay entrance. Cont. Shelf Res., 18, 1157-1177, https://doi.org/10.1016/S0278-4343(98)00036-3.

_ K. Holderied, C. Li, and R. J. Chant, 2007: Subtidal flow structure at the turning region of a wide outflow plume. J. Geophys. Res., 112, C04004, https://doi.org/10.1029/2006JC003746.

— E. Stanev, and T. H. Badewien, 2018: Tidal and subtidal exchange flows at an inlet of the Wadden Sea. Estuarine Coastal Shelf Sci., 202, 270-279, https://doi.org/10.1016/j.ecss.2018.01.013.

Walker, N. D., 1996: Satellite assessment of Mississippi River plume variability: Causes and predictability. Remote Sens. Environ., 58, 21-35, https://doi.org/10.1016/0034-4257(95)00259-6.

_ , and A. B. Hammack, 2000: Impacts of winter storms on circulation and sediment transport: Atchafalaya-Vermilion Bay region, Louisiana, U.S.A. J. Coastal Res., 16, 996-1010.

Weeks, E., M. E. Robinson, and C. Li, 2018: Quantifying cold front induced water transport of a Louisiana bay with in-situ observations using an unmanned boat. Acta Oceanol. Sin., 37 (11), 1-7, https://doi.org/10.1007/s13131-018-1330-1.

Welch, P. D., 1967: The use of fast Fourier transform for the estimation of power spectra: A method based on time averaging over short, modified periodograms. IEEE Trans. Audio Electroacoust., 15, 70-73, https://doi.org/10.1109/TAU.1967.1161901.

Williams, H. F. L., 2009: Stratigraphy, sedimentology, and microfossil content of Hurricane Rita storm surge deposits in southwest Louisiana. J. Coastal Res., 25, 1041-1051, https:// doi.org/10.2112/08-1038.1.

— , and W. M. Flanagan, 2009: Contribution of Hurricane Rita storm surge deposition to long-term sedimentation in Louisiana coastal woodlands and marshes. J. Coastal Res., 25 (56), 1671-1675.

Wilson, R. E., and R. J. Filadelfo, 1986: Subtidal current variability in the lower Hudson estuary. Physics of Shallow Estuaries and Bays, J. van de Kreeke, Ed., Lecture Notes on Coastal and Estuarine Studies, Vol. 16, Springer-Verlag, 132-142.

- K.-C. Wong, and R. Filadelfo, 1985: Low frequency sea level variability in the vicinity of the East River tidal strait. J. Geophys. Res., 90, 954-960, https://doi.org/10.1029/ JC090iC01p00954.

Wong, K.-C., 1994: On the nature of transverse variability in a coastal plain estuary. J. Geophys. Res., 99, 14209-14222, https://doi.org/10.1029/94JC00861.

— the remote and local wind effects on the subtidal exchange at the entrance to the Chesapeake Bay. J. Mar. Res., 60, 477-498, https://doi.org/10.1357/002224002762231188.

Wu, H., J. R. Zhu, J. Shen, and H. Wang, 2011: Tidal modulation on the Changjiang River plume in summer. J. Geophys. Res., 116, C08017, https://doi.org/10.1029/2011JC007209.

Xia, M. L. X., L. J. Pietrafesa, M. Peng, M., 2008: A numerical study of storm surge in the Cape Fear River estuary and adjacent coast. J. Coastal Res., 24, 159-167, https://doi.org/10.2112/06-0795.1.

Xu, H., K. Zhang, J. Shen, and Y. Li, 2010: Storm surge simulation along the U.S. East and Gulf Coasts using a multi-scale numerical model approach. Ocean Dyn., 60, 1597-1619, https:// doi.org/10.1007/s10236-010-0321-3.

Xue, L., and Coauthors, 2018: Native and non-native halophytes resiliency against sea-level rise and saltwater intrusion. Hydrobiologia, 806, 47-65, https://doi.org/10.1007/s10750-017-3333-x. 